\title{
SOBRE LA RESPONSABILIDAD SOCIAL EMPRESARIAL
}

\author{
JOSÉ MARÍA DE LA CUESTA RUTE*
}

\begin{abstract}
Resumen: La cuestión de la responsabilidad social corporativa o empresarial, fenómeno internacionalmente conocido con las siglas CSR, merece en nuestros días una consideración atenta por parte de la doctrina jurídica e incluso ha llegado a calar en el proceso legislativo. La recepción por el derecho de la doctrina de la responsabilidad social empresarial se presenta como especialmente problemática cuando la empresa se ejerce por una sociedad mercantil, singularmente si es de las llamadas sociedades de capital. Frente a la tesis contractualista de la sociedad, que es la congruente con la empresa privada como agente en el mercado, el cuño institucionalista de CSR impacta en la concepción de la empresa privada y, por lo tanto, en el sistema de economía de mercado. Particularmente, y por lo que se refiere a la relación de sociedad, CSR altera las relaciones entre propiedad y management, eliminando todo vestigio de relación representativa entre los socios y los administradores; éstos deben velar por un supuesto interés social transcendente al interés de los propios socios en cuanto que reunidos en la sociedad. Por otra parte la atención a metas propuestas en atención a la CSR borra la importancia del objeto social que se proponen los socios alcanzar mediante el contrato de sociedad.
\end{abstract}

Palabras clave: Responsabilidad; responsabilidad social; empresa; empresario; sociedad mercantil; teoría contractualista; teoría institucionalista; administración y representación; responsabilidad de los administradores; junta general; interés social; objeto social.

Clasificación JEL: K12, K22, M14.

Abstract: The question of social corporative or business responsibility, a phenomenon internationally known as corporate social responsibility (CSR), deserves consideration on the part of the judicial doctrine as it begins to pierce the legislative process. The reception of the correct social business responsibility

* Catedrático de Derecho Mercantil UCM y Abogado. Dirección: Calle Alberto Alcocer, 30 D. 28036, Madrid. Teléfono: 600978477.

Procesos de Mercado: Revista Europea de Economía Politica Vol. VIII, n.ํㅡ 2, Otoño 2011, pp. 151 a 203 
doctrine presents itself as especially problematic when businesses exercise influence over a commercial society, single-handedly if it's from capital company callings. As opposed to the company contractualist thesis, which parallels the private business as a representative in the market, the institutional stamp of CSR affects the conception of the private business and, therefore, on the economic system. Regarding relationships in a company in particular, CSR alternates the relationship between ownership and management, eliminating all traces of a representative relationship between members and administrators; these businesses should secure an evident social interest transcendent to the interest of its own members as soon as they are reunited in the company. On the other hand the attention to proposed goals regarding CSR eliminates the importance of the social object that members propose to reach by means of societal contract.

Key words: Responsibility; social responsibility; firm; entrepreneur; trading company; contractualist theory; institutionalist theory; administration and representation; responsibility of the administrators; general meeting; social interest; corporate purpose.

JEL Classification: K12, K22, M14.

\section{I \\ INTRODUCCIÓN}

La responsabilidad social corporativa o responsabilidad social empresarial es indudablemente un tema de $\operatorname{moda}^{1}$ o que "está de moda» desde hace pocos años. Y no deja de resultar curioso que lo esté dada la imprecisión de su significado que se evidencia incluso por la indecisión sobre la manera de enunciarlo. Algunos hablan de responsabilidad social corporativa mientras que otros lo hacen de la responsabilidad social empresarial; no falta algún autor ${ }^{2}$ que lo enuncia como responsabilidad social del empresario de igual forma que también en ocasiones se alude a la empresa socialmente responsable.

Las vacilaciones sobre el modo de enunciar el tema son indicativas, a mi juicio, del carácter indefinido y proteico del contenido

\footnotetext{
1 Embid (2004) p. 15.

2 Bercovitz (2010) passim.
} 
a que se refiere. Su propia ambigüedad hace dudar de que pueda en rigor considerarse que constituya un verdadero tema en el plano propio de cualquiera de las ciencias humanas o sociales. Sólo se puede decir que es un tema en el sentido de que se hace asunto de una discusión pública (DRAE). No es inadecuado pensar que, si esa discusión se abre, es porque versa sobre algo que se enuncia mediante dos palabras talismán, empresa y social, capaces de concitar a los cultivadores de diversas ramas científicas e incluso a todos los ciudadanos, y no digamos, a los políticos.

Mucho más incitativas resultan esas palabras todavía si encima se combinan con la de responsabilidad que, en el contexto, parece expresar que la empresa debe algo a la sociedad que, por lo mismo, debe serle pagado.

Creo que puede advertirse que la tematización de la responsabilidad social empresarial mucho antes que de una exigencia racional que venga impuesta por los conceptos de empresa, social y responsabilidad, corresponde, como no es nada inusual en nuestros días, a que el tema se engarza en el terreno de los sentimientos, y con tal fuerza que en el desarrollo del discurso llegan a olvidarse los conceptos o se toman aquellos que son fruto de un profundo error intelectual, e incluso moral.

Con todo, la apelación a la responsabilidad hace que el derecho tenga que ocuparse del tema, $y$, puesto que se trata de la empresa, que por naturaleza es un agente económico, corresponde ocuparse del mismo a la rama del derecho que tiene como materia a las instituciones y relaciones establecidas alrededor del mercado, es decir el llamado derecho mercantil.

La legitimación del iusmercantilista se acrecienta si cabe ante la referencia que en ocasiones el enunciado del tema hace a la corporación, que no es sino una forma de la empresa cuando el empresario es una sociedad mercantil de cierto tipo. Es decir, el tema de la responsabilidad social corporativa o empresarial no puede dejar de incitar a los mercantilistas para tomar parte en la discusión que anuncia, en la medida en que, cualquiera que sea el modo como concibamos $^{3}$ esa rama del ordenamiento jurídico privado

${ }^{3}$ El debate acerca del concepto de derecho mercantil ha perdido hoy interés tanto por la amplia descodificación que se ha venido produciendo, como porque, de una 
que llamamos mercantil, siempre tendrá como referencia material a la actividad económica en la que, sin duda, juega un papel de primordial importancia el empresario actuando mediante la empresa, y ya se trate de un empresario individual ya sea empresario una sociedad o si se prefiere una "corporación».

Ahora bien, que los juristas tengamos, como es natural, el deber de operar con conceptos jurídicos no significa sin embargo que éstos deban construirse al margen de la materia prejurídica, si puede hablarse así, que postula la normatividad jurídica. En nuestro caso esa materia pertenece al campo de la economía. Como el Digesto ya nos enseñara, el saber jurídico sólo lo será verdaderamente si se atiene a los resultados de los saberes propios relativos a la materia de las normas de las que aquél se ocupa; en nuestro caso, pues, al saber que nos procura la ciencia económica, es decir, al saber de los economistas. Entiendo, pues, que mi tarea en este punto no puede apartarse de lo que la ciencia económica nos enseña acerca de la empresa y, en concreto, de la empresa privada que se desenvuelve en un sistema de mercado. No es necesario decir que la empresa privada y el mercado obedecen a principios de libertad.

Pero es el caso que no existe un saber económico único puesto que sobre la economía se organizan distintas escuelas de pensamiento que no sólo llegan a resultados distintos, sino que disienten respecto de la naturaleza propia del saber económico y de sus métodos. A partir de la aparición en la escena de los economistas que pueden reunirse en la llamada Escuela Austriaca no puede dejar de considerarse a la ciencia económica como una ciencia humana, $\mathrm{y}$, por lo tanto, lejana a poder acomodarse a modelos matemáticos y a métodos matematizantes; así ha de deducirse al considerar que el saber económico se organiza alrededor de la acción humana. ${ }^{4}$ Razón por la que, por cierto, se produce, a mi juicio,

manera u otra, toda la doctrina acepta que una de sus instituciones centrales es sin duda la empresa así como también, en general, las instituciones del tráfico patrimonial moderno, que se efectúa en un sistema de mercado. Para una comprensión del sentido de la cuestión resulta todavía imprescindible la lectura de Rubio (1969).

4 «La acción humana» es el título de la gran obra de Mises (1949). Sobre la Escuela Austriaca de economía es indispensable la lectura de Huerta de Soto (2008); y sobre el método científico propio de la economía resulta insustituible la lectura de Hayek (1952). 
la proximidad de la ciencia económica a la ciencia del derecho que también, al menos, para quien escribe estas líneas, tiene a la conducta del hombre y del hombre empírico, o de carne y hueso, es decir, del hombre que existe en la realidad como punto de partida y como punto de llegada; el derecho tiene como centro a la persona, porque sólo en ser cauce para su perfeccionamiento en el uso de su libertad en la convivencia social encuentra el derecho su razón de ser, derecho que tiene, por otra parte, como quicio a la justicia, que exige reconocer en la persona su dignidad, su libertad y el derecho al libre desarrollo de su personalidad (cfr. arts. 1.1 y 10.1 C.E.).

Partiendo de la base de la ambigüedad respecto del contenido, en términos generales puede sostenerse que la responsabilidad social empresarial o corporativa alude a las pautas a que debe sujetarse la actuación empresarial para contribuir al logro de una sociedad mejor sin deteriorar el medio en que aquella actuación se desenvuelve. En congruencia con ello, desde un punto de vista jurídico, no puede dejar de prestarse atención al sujeto de la conducta que debe satisfacer semejantes requerimientos, y por lo pronto, pues, debe determinarse quién pueda ser ese sujeto. Es claro que en todo caso ha de tratarse de un sujeto de derecho por ser el único al que cabe imputar un comportamiento. En este sentido es razonable que algún autor, como antes se ha dicho, prefiera hablar de la responsabilidad social del empresario, ${ }^{5}$ con lo que, además de respetarse mejor el sentido del término responsabilidad, que implica imputabilidad, delimita correctamente el horizonte de la discusión por permitir que ésta acoja tanto el supuesto de que quien ejerce empresarialmente lo haga a título individual como mediante una sociedad mercantil ya que, según nuestro derecho, a toda sociedad le conviene la personalidad jurídica.

Ahora bien la mención del empresario en este contexto, es decir, como medio para superar la duda que se abre con el uso del adjetivo empresarial o corporativo es provechosa si por empresario se entiende al titular de una empresa en cuyo nombre se ejerce ésta. Es decir, si el término empresario se toma en sentido

\footnotetext{
5 Nota 2.
} 
jurídico, que se determina por la titularidad de la empresa, entendida ésta, a su vez, como conjunto organizado de bienes a efectos de la producción de bienes y servicios y de su intercambio en el mercado; esa titularidad legitima para actuar en el tráfico, es decir, ante terceros, en nombre de quien la ostenta, cuyo patrimonio queda, en consecuencia, responsable de las deudas y, en general, obligaciones contraídas en el ejercicio de la actividad.

Importa subrayar que si predicamos del empresario así entendido la responsabilidad social, se ve claro que ésta tanto puede alcanzar a la actividad productiva propiamente tal, que incluye la de disposición de los bienes y servicios que se organizan a ese fin (actividad interna como suele denominarse) como a la actividad de intercambio en el mercado de los bienes y servicios producidos (suele denominarse actividad externa). ${ }^{6}$ Este modo de ver las cosas, que es propio de un iusmercantilista, es congruente con el concepto de empresario que nos suministra la ciencia económica más solvente y que se vincula a la función empresarial, concebida como la de coordinación de medios y de fines que han sido objeto de descubrimiento (y, en su caso, generación) por su perspicacia y agudeza principalmente en la interpretación de la información que suministra el mercado a través de los precios. En vista de esa función empresarial definidora del empresario puro, ${ }^{7}$ la actuación socialmente responsable del empresario puede entenderse referida a la conducta perteneciente tanto al ámbito de la actividad interna como al de la externa. Sin duda que esto puede entenderse así sin que se plantee obstáculo alguno cuando el empresario es individual, es decir, cuando se trata de una persona natural o física, pero las cosas se complican en el caso de que la actividad externa se ejerza en nombre de una sociedad, porque entonces, si bien puede ponerse a cargo de ésta el someterse en el ámbito externo a las pautas por cuyo incumplimiento se deduciría la responsabilidad social, en el ámbito de la actividad interna es discutible que a la sociedad pueda atribuírsele una conducta por la que resulte congruente imputarle la responsabilidad

\footnotetext{
${ }^{6}$ Nótese que en realidad el empresario proyecta su actividad en un doble mercado que integra su función coordinadora; en este sentido se habla de mercados conexos.

7 Kirzner (1973) p. 59.
} 
social. Ésta cuestión que, en términos económicos, puede quedar resuelta sobre la base de distinguir entre empresario «puro»y «firma», no puede resolverse de la misma manera en términos jurídicos pues, en este campo, empresario es la sociedad, es decir la «firma», porque la definición del sujeto empresario no depende en derecho de la función empresarial rectamente entendida según la ciencia económica, sino de la titularidad que otorga la capacidad de explotación de los bienes y servicios conjuntados para la actividad productiva. ${ }^{8}$

Con los matices que se derivan de cuanto acabo de decir, considero, en efecto que la responsabilidad social debe atribuirse al empresario antes que a la empresa o corporación, pero en todo caso puede concluirse que dicho sujeto debe actuar «responsablemente» tanto por lo que se refiere al ámbito interno del como al externo, y el presente estudio ha de referirse a esa doble perspectiva.

\section{II}

\section{SIGNIFICADO DE LA RESPONSABILIDAD SOCIAL EMPRESARIAL O CORPORATIVA.}

Se hace necesario abordar la nada sencilla cuestión del significado de la responsabilidad social empresarial o corporativa. Conviene diferenciar dos planos de análisis. En primer término, debemos

\footnotetext{
${ }^{8}$ Lo que se afirma en el texto no quiere decir que no pueda ser pertinente la consideración del empresario puro en el campo del derecho a otros efectos distintos. Por otra parte, interesa llamar la atención sobre que los términos utilizados en el texto expresan la deliberada huida de hablar a secas de titularidad de la organización de los bienes para evitar el error, en otro tiempo padecido por un sector de doctrina, de que la organización constitutiva de la empresa entendida jurídicamente en sentido objetivo podía ser considerada un bien inmaterial susceptible de soportar un derecho de naturaleza semejante a los pertenecientes al género de la propiedad intelectual. Conviene ser, pues, cuidadoso con el uso de los términos en el contexto en que estamos para evitar la asociación de la titularidad del empresario sobre los bienes y servicios organizados con la titularidad dominical en sentido técnico-jurídico. Lo que no significa, conviene decirlo ya, que por este motivo haya de negarse la pertinencia a determinados efectos de la teoría de los property rights, por la sencilla razón de que, como se verá posteriormente, la referencia a la propiedad según esa doctrina no coincide exactamente con el derecho de dominio sobre los bienes.
} 
detenernos en clarificar la preferencia entre tener como referente a la empresa o a la corporación; en segundo lugar, debemos realizar el intento de dar razón de lo que podemos llamar para entendernos «naturaleza» de la responsabilidad social empresarial o corporativa, para lo que resultará indispensable pararse a señalar los ámbitos materiales en que se ha de actuar de modo socialmente responsable.

\section{1. ¿Resposabilidad social empresarial o corporativa?}

La falta de unanimidad en el modo de enunciar la cuestión es significativa de la falta de seguridad sobre lo que quiere expresarse. Parece un punto de partida seguro, sin embargo, que de la doctrina de la responsabilidad social empresarial o corporativa se hacen eco todos los que aceptan, al menos, que la empresa libre operando según el sistema de economía de mercado precisa de ciertos arreglos que la hagan «socialmente» aceptable. En efecto, incluso en alguna monografía, que publica lo que fue originariamente una tesis doctoral, se hace cuestión del enunciado del tópico para argumentar que resulta preferible aludir a la responsabilidad corporativa en vez de a la responsabilidad empresarial puesto que el uso de esta última expresión pone de manifiesto que el sistema capitalista carece «de conciencia social».9

Ahora bien, antes de optar por uno u otro término como referente del enunciado parece necesario advertir que, como ha quedado señalado, de responsabilidad no puede hablarse en términos jurídicos sin referirla a un sujeto al que puede imputarse la acción por la que deba responder. Parecería, pues, más apropiado hablar de responsabilidad social del empresario y aunque usualmente se hable de responsabilidad social empresarial, debemos entender que se alude a la responsabilidad del empresario. Ahora bien, se es empresario en tanto se ejerce la función empresarial, que se traduce en una actividad, que, por eso mismo, puede considerarse empresarial. En la mayoría de las ocasiones el ejercicio

\footnotetext{
9 Olcese (2009), pp. 41-42.
} 
de esa actividad requiere contar de manera perdurable con un conjunto de bienes y derechos especialmente organizados. Este conjunto organizado es lo que los juristas concebimos como la perspectiva objetiva del fenómeno empresarial, y es al que denominamos en general con la palabra empresa $\mathrm{o}$, a veces, como establecimiento o negocio. En todo caso, como elemento objetivo que es, de la empresa así entendida no puede predicarse ninguna responsabilidad. Podrá hacerse responsable al empresario con ocasión de la actividad desplegada mediante el conjunto organizado empresarial. Responsabilidad social empresarial equivale necesariamente, para tener sentido, a la responsabilidad del empresario por el ejercicio de su actividad empresarial.

Es interesante señalar que dentro del conjunto empresarial ha de contarse con el capital o los recursos de ese carácter que han de convertirse en los bienes de capital indispensables para la acción productiva. Pero el empresario en sentido económico no se define por razón de ser titular de una empresa en sentido objetivo, ${ }^{10}$ sino por sus dotes de perspicacia para descubrir oportunidades de ganancia, que se obtendrán en la medida en que actué como coordinador en los actos de intercambio indirecto, es decir, mediado por el dinero.

La actuación responsable del empresario no es la de quien procura la maximización del beneficio que puede obtenerse de unos recursos dados y, como en nuestro caso, organizados, sino, por el contrario, la del que descubre nuevos recursos y nuevos fines y pone su acción al servicio de coordinar unos y otros. En el límite, el personaje que debe importarnos podría perfectamente descubrir la oportunidad de ganancia, y en consecuencia, hacer suyo el beneficio que con ello se obtenga sin necesidad de disponer previamente de un conjunto patrimonial organizado. Me refiero aquí al empresario puro. De donde se deduce que la organización patrimonial que en su caso exija el aprovechamiento de la oportunidad descubierta por ese personaje ha de ser fruto de la acción de quien ya es empresario en razón de su descubrimiento

${ }^{10}$ La especialidad de la titularidad que permite disponer del conjunto organizado de bienes a efectos de su explotación se pone de relieve por Rubio (1969) pp. 499 y ss. 
previo y, por lo tanto, la tarea coordinadora de éste no sólo se produce a partir del «establecimiento» del conjunto patrimonial dispuesto para la producción de bienes y servicios sino que alcanza a la tarea previa de coordinación en los mercados de los bienes y servicios que han de ser organizados. Esto es de importancia a efectos de determinar los ámbitos a los que se extiende la exigencia del obrar responsable.

Insisto en que el empresario al que me refiero aquí se define por la función empresarial propiamente dicha y no debe ser diluida esta función en las propiamente directivas del complejo patrimonial constitutivo de la empresa en sentido objetivo en el caso de que ésta exista. En este supuesto coexisten sin que deban confundirse intelectualmente la función empresarial y la función del management y consiguientemente se debe seguir perfilando la figura del empresario puro como distinta de la de los managers. La cuestión sin embargo entraña un problema específico en el caso de que la titularidad del conjunto empresarial pertenezca a una sociedad mercantil. El problema se plantea en el caso de que exista una «firma». ${ }^{11}$ Pero ese específico problema no debe, a mi juicio, ocuparnos ahora por no tener relevancia a nuestro actual objeto. Únicamente es útil señalar que cuando la firma existe, la actuación empresarial se efectúa por ella y, en general, a partir de su existencia, se vincula a la titularidad del conjunto organizado empresarial.

Dado que la actuación socialmente responsable se refiere a la ejecutada por el empresario en el desempeño de su función de tal, parece preferible hablar de responsabilidad social empresarial antes que de responsabilidad social corporativa por resultar más expresiva de lo que verdaderamente se quiere significar. Con la responsabilidad social empresarial se acoge a toda actividad de este carácter cualquiera que sea quien la ejerza, aunque el referente que subyace al tema que nos ocupa es la gran empresa puesto que difícilmente los requerimientos que se derivan de la doctrina en cuestión resultan adecuados a las pequeñas y medianas,;

\footnotetext{
11 Kirzner (1973) pp. 69-79.

12 No obstante la ley 15/2010, de 9 de diciembre, de responsabilidad social empresarial en Extremadura destina su artículo 17 a establecer actividades de «fomento
} 
si bien será desde luego indiferente la forma jurídica y el tipo de sociedad mercantil de que, en su caso, se revista el empresario.

También por otras razones creo más acertado referir la responsabilidad social a la empresa antes que a la corporación. En primer lugar, porque no a toda sociedad mercantil le conviene el concepto de corporación; en segundo término, pero sobre todo, porque la conducta que se considera debe acomodarse a las pautas de responsabilidad social no se refiere a la que es propia de relaciones de sociedad en sentido estricto, sino que considera la conducta que tiene como centro a una empresa.

Sin embargo el análisis de la responsabilidad social empresarial no debe quedar reducido al que suscite el plexo de relaciones en que la empresa quede concernida, porque la responsabilidad social empresarial afecta también necesariamente a las relaciones internas de sociedad en el caso de que esta forma invista al empresario.

\section{Significado del termino social}

El término social resulta particularmente ambiguo. Usualmente este término sirve para designar cualquier cosa que concierna a la sociedad entendida como comunidad prepolítica. En realidad todo lo relativo al hombre - ser social por naturaleza- es relativo igualmente a la sociedad, y nada digamos de lo que concierne al derecho porque por definición éste se afirma solo en la sociedad. Por eso, con el uso aquí del adjetivo social se tiene que expresar, aunque sea implícitamente, un requerimiento o un mandato específico en vista de los concretos efectos que la acción empresarial produce para la sociedad. Incluso en la actualidad no son pocas las ocasiones en que, para justificar ciertos requerimientos por razones «sociales», se usa este adjetivo en relación

de la responsabilidad social empresarial en la pequeña y mediana empresa» con lo que el legislador extremeño tiene la pretensión de que las pequeñas y medianas empresas también se conduzcan de manera socialmente responsable. Posteriormente a dicha la ley, la de economía sostenible de marzo de 2011 extiende también la necesidad de fomentar la responsabilidad social empresarial a las pequeñas y medianas empresas. De manera semejante se ha expresado Embid (2004) pp.18 y 21. 
con determinados sectores de la sociedad, como pueden ser los integrados por quienes se sitúan en un nivel de escasa relevancia en el conjunto de la sociedad. ${ }^{13}$

Con todo, considero que podemos convenir en que ser responsable socialmente significa comportarse de acuerdo con unos estándares de conducta que se reputan imprescindibles para salvaguardar intereses que por ser de todos se dicen de la sociedad. Siendo esto así, la palabra responsabilidad sólo tendría significado jurídico cuando de no atenerse a esos estándares se siguiera para el sujeto una sanción capaz de imponerse coactivamente. ${ }^{14}$ Como quien sufre la acción «irresponsable» es, por definición, un sujeto universal y difuso, tal sanción no podría imponerse más que por las vías y por los órganos del derecho punitivo y no sería razonable que consistiera en la reparación de un daño. ${ }^{15} \mathrm{El}$ carácter preventivo que se atribuye a la responsabilidad social empresarial hace que la referencia a lo social lleve implícita la creación de un título habilitante para la intervención pública en el desarrollo de la actividad de que se trate; y, en nuestro caso, de la actividad económica. Se me hace por ello imposible aceptar la consideración de algún autor ${ }^{16}$ de que la doctrina de la responsabilidad social es un elemento que robustece, al justificarlo, el sistema de economía de mercado. Hay en esta apreciación una presuposición de que el sistema capitalista presenta por lo menos lunares que precisan ser corregidos para no ser rechazable. Con independencia de otras consideraciones, es de señalar que no se percibe por quienes así piensan que con la intervención pública no se fortalece el sistema, sino que se destruye. La

13 Me resisto a hablar de sectores sociales menos favorecidos o desfavorecidos porque no puedo participar de la creencia en que la posición «social» de cada uno dependa de ninguna clase de favor que pueda ser dispensado aleatoriamente por un sujeto. En mi opinión, en plena modernidad en el más noble y mejor de sus sentidos, la posición social de cada uno es fundamentalmente fruto y resultado del propio esfuerzo y de las propias metas.

14 Bercovitz (2010) p. 65.

15 Dejo al margen los excesos e incluso extorsiones a que se prestan las reciente y discutibles «acciones de clase» que pueden ejercitarse ante los tribunales de justicia de orden civil y que en rigor, no son sino una muestra más del constructivismo voluntarista en el campo del derecho.

16 Embid (2004) p. 17. 
responsabilidad social empresarial es manifestación o rasgo definitorio de posiciones constructivistas y consiguientemente socialistas en cualquiera de sus obediencias que cifran en la intervención estatal el remedio a supuestos males «sociales» que sólo gracias a esa intervención pueden además prevenirse; este es el fundamento de la atribución a los poderes públicos de la función de «dirección de la economía», eufemismo que apenas encubre pudorosamente la aceptación de la economía mixta o de la llamada «economía social de mercado»; en definitiva que confía al Estado el quehacer o función de proporcionar a los ciudadanos el «bienestar - ¿cómo no?- social».

Es digno de subrayar que con el adjetivo social aplicado a la acción empresarial se hace patente que se piensa que la acción empresarial no es de suyo una acción social. Como negar de cualquier acción humana su carácter social es sencillamente imposible por el inesquivable carácter transitivo de la acción y de sus efectos hasta alcanzar reductos sociales desconocidos, la implícita negación del carácter social de la acción empresarial que representa hablar de la responsabilidad social de la empresa ha de suponer que con este término se alude a ese plus de consideración de la sociedad en su conjunto a que me acabo de referir. Anticiparé aquí mi convicción de que la acción empresarial representa, especialmente en el caso de libre empresa, una acción de servicio hacia otros en el sentido más pleno de la palabra y, por lo tanto, de tan considerable densidad social que no necesita adornarse con el pleonasmo que representa su caracter social. Por lo que, si así se requiere, será porque se tiene un concepto incorrecto de la acción empresarial o porque con lo social se alude a segmentos concretos de la sociedad, lo que supone también concebir a la empresa de modo tan reduccionista como de nuevo equivocado.

Aun cuando no es fácilmente determinable lo que queda concernido al hablar de responsabilidad social empresarial por la diversidad de puntos de vista y aportaciones, indicativos, por lo demás, de su falta de consistencia conceptual, podemos no obstante indicar genéricamente que se expresa la necesidad de que al llevar la acción empresarial adelante se consideren los grupos de quienes se pueden estimar portadores de un interés en relación con la misma debido a su incidencia sobre ellos. Estos grupos 
de interesados, llamados stakeholders, serán necesariamente distintos según las circunstancias de cada caso, de la misma manera que los intereses de los diferentes grupos son de hecho de muy distinta naturaleza. ${ }^{17}$

Se comprende entonces que resulten muy variados los ámbitos sobre los que se proyecta la responsabilidad social empresarial.

III

\section{NATURALEZA DE LA RESPONSABILIDAD SOCIAL EMPRESARIAL}

De responsabilidad social empresarial o corporativa no sólo hablan los políticos y algunos académicos, sino que incluso tratan de ella documentos internacionales y también otros procedentes de distintas instancias de la Unión Europea así como, en nuestra patria, textos jurídicos de índole normativa.

Una primera cuestión se plantea alrededor de si la responsabilidad social empresarial pertenece al reino de la voluntariedad o, por el contrario, al de la coacción. En términos generales suele adscribirse al primero. Pero esto no es suficiente, según veremos en seguida, para entender plenamente de lo que se habla ni el por qué se habla de ello. En todo caso la responsabilidad social empresarial implica un comportamiento, y, en este sentido, evoca unas pautas de conducta; en consecuencia esas pautas se presentan como tales por considerar deseable que se observen en la actividad empresarial. Y entonces la pregunta resulta insoslayable: ¿de qué orden estimativo o valorativo se deriva el carácter bueno de esa conducta? A esta pregunta no da respuesta el hecho de que a semejantes pautas buenas pueda atenerse voluntariamente el sujeto, puesto que el ámbito de la voluntariedad si bien es

17 El pluralismo de los intereses puede llegar a alcanzar un ámbito holístico que se ve favorecido por los procesos de globalización de la economía, que se convierten en motivo de postulación de una autoridad mundial que debiera ser garante de la totalidad de esos intereses abstractos y verdaderamente globalizados. No hay que señalar que éstas propuestas no serán más que el límite del camino iniciado ya con la aceptación de la doctrina de la responsabilidad social de la empresa. 
el propio de la ética, no es tampoco extraño al derecho, que, a veces, expresa sus normas como dispositivas. Por lo demás, ni siquiera la ética y el derecho agotan los órdenes valorativos de los que descienden las buenas prácticas, pues no pueden olvidarse los llamados usos sociales.

Atribuir a uno u otro de esos órdenes la pertenencia de los criterios estimativos de la conducta es algo del mayor interés. No sólo para poder calibrar las consecuencias de la inobservancia de las pautas de referencia, sino además para tener a esas pautas como elemento indispensable en el momento de la valoración, conceptualización previa y consiguiente interpretación de las normas destinadas a la empresa y la sociedad mercantil con carácter general y, por lo tanto, incluso en aspectos que se encuentran al margen de la responsabilidad social. Por poner un ejemplo claro, el interés social, que es concepto central del derecho de sociedades, no podrá entenderse de la misma manera si se parte de que la sociedad ejerciente de una actividad empresarial debe comportarse de manera socialmente responsable o si no es así.

Pues bien, es aceptado por lo general que la responsabilidad social empresarial se adscribe al terreno de la voluntariedad. Así se deduce incluso de las conclusiones obtenidas del debate sobre el particular que en la Unión Europea se abrió en 2001 con el llamado Libro Verde ${ }^{18}$ según se subraya en la Comunicación de la Comisión de 2002. ${ }^{19}$ El carácter voluntario se mantiene por la doctrina jurídica en el sentido de que las pautas de comportamiento «responsable» no se encuentran todavía establecidas por normas jurídicas de carácter general. Con todo, si miramos con atención observaremos que la adscripción de los estándares de conducta al terreno de la voluntad no tiene otro alcance que no sea el de excluir que el obrar «irresponsable» tenga una sanción directamente punitiva por parte del derecho, pero eso no evita que los

18 Libro Verde - Fomentar un marco europeo para la responsabilidad social de las empresas, COM (2001) 366, Julio de 2001 http: / / eur-lex.europa.eu / LexUriServ / site/es/com/2001/com2001_0366es01.pdf.

${ }^{19}$ Comunicación de la Comisión relativa a la responsabilidad social de las empresas: una contribución empresarial al desarrollo sostenible, COM (2002) de Julio 2002 http: / / eur-lex.europa.eu/LexUriServ/LexUriServ.do?uri=COM:2002:0347:FIN:es:PDF. 
criterios conformadores del obrar «responsable» no se tomen como guías cuando no por verdaderos principios informadores de conceptos e instituciones jurídicas con arreglo a los cuales, en consecuencia, se ha de efectuar toda la tares interpretativa de las normas correspondientes y, en definitiva, toda la tarea de "realización» del derecho. A estos efectos no es precisamente irrelevante que los autores que se han ocupado con mayor autoridad de nuestro tema, si bien reconocen que la responsabilidad social empresarial no se impone por el momento por normas jurídicas coactivas, al mismo tiempo afirmen que pueden encontrarse asistemáticamente vestigios suyos en distintos textos normativos. ${ }^{20}$ Esto solo puede sostenerse sobre la base de lo que acabo de señalar, esto es, de que se toman por vestigios los conceptos tradicionales recogidos en normas no menos tradicionales pero sometidas a una reinterpretación a la luz del nuevo paradigma. Por lo demás, una aparente excepción a la voluntariedad se encuentra en la Ley autonómica 15/2010, de 9 de diciembre, de responsabilidad social empresarial en Extremadura. También la Ley estatal de Economía Sostenible cobija una referencia a la cuestión en ese mar sin orillas que constituye su contenido.

Sin perjuicio de volver sobre esas dos leyes en particular, interesa que nos detengamos en este momento en considerar la valoración que merece desde el punto de vista jurídico la noción de responsabilidad social empresarial cuando se la mantiene en el ámbito de la voluntariedad. Si se considera al actuar socialmente responsable como deber ético, ${ }^{21}$ la cuestión entraña unas consecuencias aparentemente mucho menos significativas que las que se derivan de estimar que el actuar responsable debe atenerse a pautas establecidas por el consenso social. Por supuesto que ambas posturas no son incompatibles pero, mientras que ante una conducta éticamente mala no es esperable en la actualidad ninguna reacción socialmente adversa, en cambio, reacciones de ese carácter pueden esperarse de quien no se ajusta a comportamientos acordes con la opinión común establecida por el pensamiento débil que es el propio de lo políticamente correcto sin

20 Esteban (2005) pp. 43-46.

21 Argandoña-Weltzein (2009) passim. 
cuidado de que se ajuste o no al orden moral, incluso aunque lo contradiga.

Cabalmente por la coacción que ejerce la «tiranía» del uso social así afirmado, es por lo que no está desacertado pensar que el sujeto ejerciente de una empresa se sentirá inclinado a actuar según las pautas reconocidas por la opinión como exigibles para ser un sujeto merecedor de reconocimiento y estima, y nótese que estos reconocimiento y estima no solo tienen significación en el orden de los honores o distinciones honoríficas, sino mucho más crudamente en el orden puramente económico de aceptación de los productos o servicios que el empresario ponga en el mercado. Pensemos en el tópico del «comercio justo» y lo que representa para el mundo económico en sí y para los intercambios de índole internacional, eso sin contar con los efectos que produce sobre el desarrollo de los pueblos que se afirma querer proteger con tópicos como el señalado.

¿Cómo puede negarse que la coacción social forzará no ya solo la libertad de los empresarios en cuanto a sus concretas acciones, sino en, lo que parece más digno de consideración por nuestra parte en un trance como el actual, la forma de proponerse la acción empresarial misma?, ¿cómo negar la influencia de esa coacción social sobre la normatividad jurídica relativa a la acción empresarial y sus formas de ejercerla?, ¿cómo se podrá prescindir de la opinión acerca del obrar correcto a la hora de establecer económica y, sobre todo, jurídicamente los conceptos de empresa y empresario?

Sobre la base de considerar bueno, al menos, mejor que su contrario, el actuar socialmente responsable se lo tendrá por paradigma interpretativo de las normas jurídicas que, puesto que se alumbraron sin cuidado de ese paradigma, serán sometidas al socorrido y abusivo método del «uso alternativo» que ni siquiera exige a los hombres de leyes que lo aplican que se tomen la molestia de forzar el cambio de las normas. De aquí deducimos que el tema de la responsabilidad social empresarial o corporativa es un tema que pertenece al terreno de la ideología; no se desprende de una conceptualización precisa y acorde a las exigencias de la metodología científica ni jurídica ni económica. Es algo que viene impuesta desde fuera por criterios consecuencialistas que 
se traducen, en el orden de la economía, en la negación de la libre empresa, por supuesto privada y operativa en un sistema de mercado, y, en el orden jurídico, en la conversión de la normatividad propia del derecho, en reglas del llamado «derecho regulatorio», que es debido a un regulador omnisciente y por ello «fatalmente arrogante» que, como por mucho que lo lamente es tan ignorante como cualquiera, tiene que variar constantemente las reglas a impulsos de sus ocurrencias voluntaristas. ${ }^{22}$

Llegado el momento de delimitar los sectores a que concierne la responsabilidad social empresarial y en congruencia con todo lo anterior, es necesario decir que, pese al manoseo del tema que nos ocupa, pese a que se le atribuye la pertenencia a un linaje de pretendido abolengo, pese a que se ocupen de él los órganos burocráticos de rango internacional, pese a que, en fin, hayan podido picar el anzuelo algunos hacedores de textos que solamente por la forma de producirse y de publicarse pueden llamarse leyes, pese a todo ello, no se consigue establecer ni siquiera el elenco de sectores en que el tema de marras deba encontrar aplicación y desarrollo; se trata de algo que permanece abierto. Es notable a estos efectos que en trance de definir la responsabilidad social empresarial o corporativa, las propias autoridades comunitarias que lo han pretendido, según se deduce explícitamente de sus textos, no salgan de la generalización de que consiste en atender a los grupos de interesados que quedan concernidos con la acción empresarial. ${ }^{23}$

22 Es inaceptable, sencillamente porque no es verdad, el frecuente reproche de que también es ideológica la posición que se mantiene en el texto. No es ideológica una posición que respeta la naturaleza de las cosas y deja hablar a los hechos y a la realidad.

${ }^{23}$ El Libro Verde de la Unión Europea define (porque tiene la deliberada pretensión de definir) la responsabilidad social «como la integración voluntaria, por parte de las empresas, de las preocupaciones sociales y medioambientales en sus operaciones comerciales y sus relaciones con sus interlocutores». Ésta definición se recoge por la Comunicación de la Comisión de 2002 que parte de ella. Literalmente idéntica es la definición contenida en el artículo de la ley extremeña de 9 de diciembre de 2010. De criterios semejantes parte el Pacto Mundial de las Naciones Unidad que al filo del año 2000 se propuso «sincronizar la actividad y las necesidades de las empresas con los principios y objetivos de la acción política e institucional de las Naciones Unidas». Bien es cierto que al enunciar los diez principios dicho Pacto nos muestra los campos de intereses sobre los que se proyectan y que van desde el respeto a los derechos humanos a la lucha contra la corrupción pasando por las relaciones laborales y la 
Tanto en los documentos comunitarios como nacionales se insiste en proclamar la voluntariedad con que se proponen los campos en que el empresario debe conducirse responsablemente y se señala también que los requerimientos que se siguen de esas propuestas van más allá del cumplimiento de las leyes. Por cierto que no deja de ser un contrasentido por lo que a la legislación interna se refiere que la conducta dirigida pretendidamente a salvaguardar intereses públicos considerados, al parecer, tan de primera magnitud como para utilizar la forma de la norma de superior rango de entre las jurídicas, únicamente se proponga como paradigma al que voluntariamente pueda uno atenerse o no, sin que de esto segundo se siga ninguna sanción propiamente jurídica. Creo que ello es la mejor prueba de que la responsabilidad social empresarial es un tópico surgido de la ideología constructivista que en términos económicos y, lo que es peor, jurídicos se manifiesta en el intervencionismo más descarado con el propósito, por lo demás, declarado de promover el «bienestar» social. ${ }^{24}$

tutela del medio ambiente. La verdad es que el sobrecogimiento de uno ante semejantes documentos probablemente se deba al recuerdo que le traen de Moisés descendiendo del Sinaí con las Tablas de la Ley; y no porque el acto de dar a conocer los documentos que nos ocupan tengan la grandeza del episodio mosaico, sino porque inevitablemente la consecuencia que uno extrae es la de que hay que ser genéricamente bueno. Pero en nuestro caso no se sabe por qué razón esa estupenda regla del comportamiento tiene que referirse sólo a los empresarios y precisamente en cuanto ejercientes de la empresa.

${ }^{24}$ El artículo 39 de la Ley de Economía Sostenible es la mejor muestra de lo que digo y merece la pena transcribirlo para comodidad del lector:

«1. Con el objetivo de incentivar a las empresas, organizaciones e instituciones públicas o privadas, especialmente a las pequeñas y medianas y a las empresas individuales, a incorporar o desarrollar políticas de responsabilidad social, las Administraciones Públicas mantendrán una política de promoción de la responsabilidad social, difundiendo su conocimiento y las mejores prácticas existentes y estimulando el estudio y análisis sobre los efectos en materia de competitividad empresarial de las políticas de responsabilidad social.

En particular, el Gobierno pondrá a su disposición un conjunto de características e indicadores para su autoevaluación en materia de responsabilidad social, así como modelos o referencias de reporte, todo ello de acuerdo con los estándares internacionales en la materia.

2. El conjunto de características, indicadores y modelos de referencia a que se refiere el apartado anterior deberá atender especialmente a los objetivos 
Aunque, como antes se dijo, el elenco de sectores concernidos por la cuestión de la responsabilidad social empresarial se mantiene abierto, ${ }^{25}$ sin embargo creo que cabe establecer dos grupos mayores de portadores de intereses afectados por la actuación empresarial. El primero lo formarían aquellos que prestan su concurso a la actividad del empresario de tal manera que no pueden considerarse totalmente ajenos a la empresa. Se incardinarían, en efecto, en la empresa entendida como establecimiento o como conjunto organizado de bienes. Así, es muy común referirse al grupo formado por los trabajadores, respecto del que sería digno de considerar, además de su condición de contribuyentes con servicios o actividad al proceso productivo, todo lo que hoy concierne a la llamada conciliación de la vida familiar y laboral así como, reflejamente, a la igualdad de sexos, y, en general, al principio de no discriminación.

Cuando se trata del supuesto del ejercicio empresarial por una sociedad mercantil se plantea indudablemente la cuestión de si los socios han de considerarse integrados en un grupo a efectos de ser considerados desde el punto de vista del ejercicio socialmente responsable de la actividad. Pero sobre este particular hemos de volver más adelante aunque no sin dejar constancia ya de nuestra posición negativa.

de transparencia en la gestión, buen gobierno corporativo, compromiso con lo local y el medioambiente, respeto a los derechos humanos, mejora de las relaciones laborales, promoción de la integración de la mujer, de la igualdad efectiva entre mujeres y hombres, de la igualdad de oportunidades y accesibilidad universal de las personas con discapacidad y del consumo sostenible, todo ello de acuerdo con las recomendaciones que, en este sentido, haga el Consejo Estatal de la Responsabilidad Social Empresarial, constituido por el Real Decreto 221/2008, de 15 de febrero, por el que se regula el Consejo Estatal de Responsabilidad Social de las Empresas.»

Como queda patente, se trata de dar fundamento a unas políticas que justifiquen la intervención en todos los sectores a los que especialmente se refiere el apartado 2 del precepto.

${ }_{25}$ No podrá cerrarse nunca pues es inherente a toda la ideología constructivista que siempre puedan discernirse sectores nuevos, creados artificialmente por la propia intervención, para los que supuestamente se demandará de nuevo la intervención del «constructor». Ésta es la causa de la que se sigue el pernicioso efecto de una masiva producción normativa bajo la capa formal de leyes que no son, por lo demás, sino manifestación del más crudo positivismo legalista. 
Por el extremo opuesto, es decir, el de mayor lejanía al núcleo de la empresa, es incuestionable que la preocupación por el medio ambiente es hoy, con justificación o sin ella, compartida por amplios sectores de la población como cuestión que afecta en general a toda la humanidad. Por eso mismo es imposible identificar a los portadores del interés sobre esa materia que, por lo mismo, se considera de interés general, incluso a escala global. ${ }^{26}$

La adscripción al ámbito interno o externo a la empresa deja de ser simple cuando se considera que, por lo general, los partidarios de la responsabilidad social empresarial incluyen entre los grupos de interesados tanto a los proveedores de materias primas o de componentes para la fabricación como a los consumidores o potenciales clientes. ${ }^{27}$

No puede negarse que resulta paradójica la insistencia en el comportamiento correcto del empresario según criterios de responsabilidad social hacia proveedores y, sobre todo, consumidores. Sólo se comprende si se recapacita en que quienes hacen de la responsabilidad social empresarial un tema de análisis en especial jurídico están muy lejos de tener un concepto de empresa como agente económico que no sea erróneo; y no hay que decir que me refiero, por supuesto, a la empresa privada que actúa en el mercado, es decir, a la empresa a la que se refiere el artículo 38 de la Constitución. Porque no puede concebirse que una empresa opere en contra de sus proveedores y, sobre todo, de los consumidores, puesto que sólo mediante un comportamiento adecuado en los mercados respectivos la empresa se asegura su propia pervivencia. Al margen ha de quedar, por supuesto, la normatividad jurídico-penal. Este desconocimiento de la empresa hace

${ }^{26}$ Muy directamente relacionado con esto se encuentran las, en la mayoría de los casos quiero creer que irreflexivas, solicitaciones de una «autoridad» mundial.

${ }^{27}$ La extensión de la responsabilidad social empresarial es aleccionadora en Alfonso (Dir.y Cor) (2010). Basta repasar el índice de este libro colectivo para apreciar que prácticamente todos los sectores del derecho mercantil se considera que deben adecuarse a los criterios del obrar socialmente responsable. El libro desarrolla lo que ya estaba incoado en Embid (2004) que no en balde es autorizado prologuista de la obra que ahora se cita y que abarca incluso a la conducta tributaria socialmente responsable. Considero que se confirma que el tópico del que en este trabajo me estoy ocupando no pasa de ser un punto de vista (ideológico) desde el que contemplar todo el comportamiento empresarial según las normas de derecho. 
necesario que también hayamos de contemplar desde la perspectiva de su correcta noción la cuestión de la responsabilidad social empresarial, como después haremos.

Tras este no breve excursus, creo que podemos concluir que resulta muy difícil precisar la naturaleza de la responsabilidad social empresarial desde el punto de vista jurídico. Se nos ha hecho patente, desde luego, que la cuestión concierne al concepto de la función empresarial lo mismo que al concepto de sociedad mercantil cuando ésta sea la investidura del titular de la empresa en sentido objetivo. De estas cuestiones volveremos a ocuparnos más abajo.

Pero en este punto en que nos encontramos ahora podemos afirmar que para un jurista la cuestión problemática de la responsabilidad social empresarial se plantea en el nivel de las fuentes del derecho. Y no sólo en un sentido formal, porque también afecta, y entiendo que principalmente, a las fuentes en sentido material. Empezando por esto último se ha de manifestar sorpresa en primer lugar ante el hecho de que la responsabilidad social empresarial se enuncie en textos legales que sin embargo reconocen que observar la conducta adecuada al comportamiento responsable pertenece al reino de la voluntariedad. Lo que no parece muy acorde con la consideración de un verdadero deber de conducta cuya imposición sería lo congruente con la pretendida salvaguarda de intereses generales, casi universales; porque, de quedar éstos comprometidos y siempre que representaran un verdadero bien común, deberían ser objeto de "cuidado» por parte de los poderes públicos, cuya existencia cabalmente se justifica, como los clásicos ya enunciaron, por el cuidado que les está encomendado de la sociedad respecto del bien común, cuidado que debiera traducirse en nuestro caso en deberes de conducta verdaderos en sentido técnico-jurídico. Como no es así, hay motivos pues, para dudar de que, en efecto, los supuestos intereses generales sean constitutivos del bien común. Pero en tal caso se ignora la razón por virtud de la cual tenga que promulgarse nada menos que una ley formal para referirse a unas genéricas pautas del obrar.

Por mucho que se haya degradado el concepto de ley y el uso de ésta, parece que una ley no debe ser utilizada como instrumento que exprese, no verdaderos mandatos, sino recomendaciones 
y propuestas como incentivos para que se observe una determinada conducta. En este sentido es interesante subrayar que, según los textos legales nacionales, la adecuación de la propia conducta a las pautas de la responsabilidad social empresarial originará el otorgamiento de premios y el derecho de uso de emblemas en el ámbito de las comunicaciones comerciales, previa la correspondiente auditoria y la consiguiente anotación en un registro de índole administrativa. Es altamente significativo que la Ley de Economía Sostenible de 2011 expresamente se refiera a la posibilidad de que las sociedades anónimas publiquen anualmente sus políticas de responsabilidad social en un informe ad hoc. ${ }^{28}$

En vista de todo ello parece obligado concluir que la inadecuación de la ley al objetivo que se persigue, que, por cierto, impide acudir al socorrido recurso de las leyes-marco u otros semejantes, es una muestra más que patentiza la conclusión, ya avanzada pero en la que no importa insistir, de que la responsabilidad social empresarial pertenece al campo de la retorica ideológica propia de la ingeniería social que, en este caso se instrumenta, además, mediante una tarea formalmente pedagógica gracias al uso de la ley, que robustece la errónea e infundada creencia de los ciudadanos de que el empresario privado al actuar en el mercado no se sujeta de facto al paradigma de la responsabilidad social. El otorgamiento de medallas y distinciones por parte de las leyes no pertenece en verdad al campo de la «justicia distributiva» entendida al modo tradicional, esto es, como determinante del reconocimiento de los sujetos y de su honor en atención a su conducta, sino en el mejor de los casos entendida al modo como se hace desde posiciones ideológicas determinadas. ${ }^{29}$

La cuestión de las fuentes a que me refiero no es meramente teórica. Aparte de las consecuencias negativas que tiene para el

28 Vale la pena recordar en este punto que ya en febrero de 1981 por iniciativa del Banco de Bilbao se celebraron unas Jornadas de Estudio sobre «El Balance Social de la Empresa y las Instituciones Financieras». Fruto de las Jornadas fue la publicación, en 1982, de la obra colectiva con ese título. En esas Jornadas tuve ocasión de expresar mi punto de vista en la Ponencia recogida en dicha obra, pp. 253-270.

29 Véanse las citadas leyes españolas. 
concepto de ley, las tiene también en relación con el tema que actualmente nos ocupa; la pedagogía a la que me acabo de referir potencia la creencia común acerca de cómo ha de desenvolverse una actividad empresarial y, puesto que, como veremos, las pautas de conducta del obrar responsable son inconsistentes con los correctos conceptos de empresa y de actividad empresarial, terminarán arrinconándose éstos y cambiándose por otros nuevos absolutamente erróneos desde el punto de vista científico además de disfuncionales desde un punto de vista técnico. En el campo del derecho, el abandono de los correctos conceptos económicos hará que se multipliquen las normas, que serán ya cogentes, relativas a la empresa y a la sociedad mercantil, de modo que los adecuados conceptos jurídicos de una y otra realidad quedarán desfigurados; con ello se traicionará la verdadera función del derecho respecto de la actividad económica. La extensión de la falsa creencia a impulsos de la difusión de la doctrina de la responsabilidad social empresarial por medio de textos «formalmente» normativos obrará como razón de - aparente- legitimación para producir continuas normas que, aún con la apariencia de carácter verdaderamente jurídico, no pasarán de ser sin embargo de índole «regulatoria».

\section{IV CONCEPTO Y FUNCIÓN DE LA EMPRESA Y RESPONSABILIDAD SOCIAL EMPRESARIAL}

Aún cuando anteriormente han quedado señalados los rasgos definitorios de la función empresarial y de la empresa conviene, no obstante, extenderse, siquiera sea mínimamente, en considerar la compatibilidad del concepto de empresa que se estima correcto con lo que se deriva de la llamada responsabilidad social empresarial. Algunos rasgos de la cuestión ya han sido anticipados.

La empresa es expresión de la función de coordinación entre recursos y necesidades que realiza el sujeto llamado empresario y que es fruto de su perspicacia para percibir la ganancia o beneficio que puede seguirse de esa actividad coordinadora. La función empresarial tiene como presupuesto de hecho la división 
del trabajo y, desde el punto de vista jurídico, la institución del derecho de propiedad. En razón de una y otro cabe que el empresario efectúe la función coordinadora que le es propia. El ejercicio de la función empresarial supone un momento creativo en el que consiste realmente la almendra de esa función. El empresario es quien descubre y saca a la luz nuevos recursos y nuevos fines a los que aquellos se pueden aplicar como medios. Éste es el sentido dinámico en que puede y debe hablarse de eficiencia económica. ${ }^{30}$ La función empresarial y la empresa no pueden concebirse al margen del mercado. Rectamente entendido, el mercado consiste en el medio de información acerca de las actitudes de oferentes y demandantes respecto de todas las acciones de cambio indirecto, es decir, mediado por el dinero, de los bienes y servicios. $\mathrm{Si}$ bien esas acciones tienen su origen en la voluntad de personas desconocidas y aisladas, al confluir en el mercado, puede obtenerse del conjunto la información sobre los deseos, las actitudes, las necesidades de la gente; la información, que sustancialmente se condesa en el sistema de precios, es presupuesto para el cálculo económico que necesariamente está en la base de la función del empresario. Es interesante notar que la información que el mercado suministra se refiere siempre a un pasado, por lo que al tomar ocasión de ella el empresario para realizar su tarea coordinadora, es decir, empresarial, no deja de actuar con una incertidumbre respecto del futuro, de ahí que puede errar, pero del error en su caso extraerá el empresario nuevo conocimiento. Es de interés subrayar que ese conocimiento que fundamenta la acción empresarial se va convirtiendo en tal sobre la base de la información, incontrolable a priori, que el mercado va suministrando así como sobre la base de la propia experiencia.

Como han puesto de relieve los maestros austriacos, la ignorancia es el elemento nuclear de la acción empresarial. A remediar esa ignorancia se dirige el orden espontáneo en que consiste el mercado, que sin embargo sólo en parte la elimina puesto que siempre permanecerá un resto de incertidumbre. Es absolutamente capital darse cuenta de que el mercado es el único medio, excluida

30 Huerta de Soto (2004) passim. 
la experiencia, que, por lo demás, también se asienta en el mercado, transmisor de información y conocimiento capaz de vencer la ignorancia por lo que se refiere a fines y a medios. Sentado esto, resulta un contrasentido pensar que pueda existir un sujeto adornado de un conocimiento sobre las necesidades, sobre los recursos y sobre los fines superior al que puede obtenerse de la realidad del mercado y que por ser ajeno a éste tendría que ser considerado infuso. Esto naturalmente si se descarta la pretensión de obtener el conocimiento sobre la base de constructos mentales que nada tienen que ver con el comportamiento de los hombres.

Un rasgo que también debe tenerse en cuenta en un trabajo como éste es el que deriva de la concepción de la eficiencia dinámica puesto que el dinamismo que le es inherente excluye para cualquier momento que se considere la idea de equilibrio, que, si no hay inconveniente para aceptarlo como meta o diana, precisamente por serlo tendrá carácter permanente pues nunca llegará a hacerse realidad, con lo que no será posible considerar ninguna situación de equilibrio en ningún hipotético punto de partida ni tampoco en el no menos hipotético de llegada. En este sentido, el mercado sólo puede concebirse como proceso y, por lo tanto, no resulta adecuado hablar de «fallos del mercado» a los que poder achacar las llamadas externalidades negativas que debieran excluirse por los poderes públicos. Algunos autores se refieren a los criterios pertenecientes al haz de preocupaciones de la responsabilidad social empresarial como medios necesarios para prevenir las externalidades negativas, poniendo así ciertamente en evidencia que la responsabilidad social empresarial es un título habilitante para la intervención pública de la economía.

La concepción de empresa que se desprende de las premisas sentadas es, sin duda, la que responde al saber económico como saber práctico referido por consiguiente al mundo real; es también la que sin duda prevé el artículo 38 de la Constitución Española que no en balde invoca al sistema de economía de mercada al hablar del derecho de libertad de empresa. En consecuencia ninguna de las ramas del derecho, y en concreto la denominada Derecho Mercantil, no puede, sin traicionar su función, considerar la empresa y el mercado de manera distinta a la que aquí se sostiene. 
Quizá no sea inapropiado dedicar unas líneas a que, por lo que al punto de vista jurídico concierne, es indiferente en este momento la cuestión de si es apropiada o no la llamada «teoría contractual de la empresa» ${ }^{31}$ para dar explicación del fenómeno empresarial porque, aunque se parta de dicha teoría, es incuestionable que en la actividad dirigida a la organización por el empresario del conjunto de bienes que se integran en la empresa en sentido objetivo, el empresario se atiene a los procesos de los mercados respectivos siendo entonces indiferente, a estos efectos, que se considere que, una vez establecida la empresa, las relaciones internas puedan considerarse al margen del mercado y, en consecuencia, la empresa se conciba como alternativa de éste. ${ }^{32}$

Debiéndose, pues, por definición la empresa a los deseos de sus clientes potenciales y actuales (la famosa «soberanía del consumidor», que si no puede hacerse plenamente efectiva ello es debido a la falta de libertad «real» de los mercados tan profusamente intervenidos), es un contrasentido que se considere como ámbito al que se extiende la responsabilidad social empresarial el relativo al grupo que forman los llamados consumidores. A los consumidores la empresa debe satisfacerlos en lo que es propio de una y otros y que consiste en cubrir una necesidad de la manera menos costosa y, en general, más satisfactoria posible. Otro tanto cabe decir con el grupo de proveedores de la empresa $y$, en general, de suministradores de bienes y servicios a la misma.

Por lo tanto la insistencia en la actuación socialmente responsable frente a consumidores y proveedores de la empresa es sencillamente un contrasentido lógico que pervierte el recto concepto de empresa y de la función del empresario.

Por otra parte, es claro que, con independencia de toda la retórica de que quieran adornarse los partidarios de la doctrina de la responsabilidad social de la empresa, la acción empresarial, es decir en el cumplimiento de su función, el empresario al procurar

31 La teoría contractual de la empresa puede tener interés para el tema que tratamos luego al proyectar el estudio sobre la sociedad que ejercite la empresa; en relación con una proyección así y críticamente, Gondra (2010).

32 Schwartz (1981) pp. 162 ss. 
su propio interés, es decir, la legítima obtención de la ganancia o el beneficio empresarial, es indiscutible que adopta una actitud objetivamente servicial hacia los demás. ${ }^{33}$

La concepción de la empresa que aquí se mantiene hace igualmente impertinente tener que acudir a la instancia de la responsabilidad social empresarial para deducir la conducta del empresario en relación con los trabajadores de la empresa. E insisto en que, a estos efectos, es indiferente atenerse o no a la teoría contractual de la empresa porque, en todo caso, el recurso que constituye el servicio o la actividad de los trabajadores se consigue mediante contratos en un mercado.

Establecido así el concepto de empresa que es acorde con la actividad de producción e intercambio de bienes y servicios en el mercado, este concepto es el apropiado a la naturaleza del fenómeno empresarial. Lo que en el orden regular de una sociedad gobernada por el derecho significa que la empresa cumple con su «función social» cuanto más eficientemente responde a su propio fin. Esto es lo que la sociedad debe reclamar de una empresa; de que efectivamente lo reclame depende, más bien debe depender en sentido jurídico (pienso ahora en la institución del concurso de acreedores), tan sólo que la empresa perdure. De tal manera que ningún maquillaje o cosmética propiciados desde los poderes públicos, como puede ser la referencia a la responsabilidad social empresarial, debe ocultar que, para bien y para mal, la sanción al recto proceder del empresario debe ser únicamente otorgada por el mercado. Naturalmente más inaceptable todavía sería el caso de que a la función empresarial se le impusieran verdaderos deberes en razón de la responsabilidad social empresarial pues que entonces interferirían tales deberes con el deber propio de toda empresa.

Cuanto acaba de decirse nada tiene que ver con que la persona del empresario o las personas que integran el «empresario social» no hayan de comportarse con arreglo a principios morales. Pero esto, naturalmente, no es algo que concierna al empresario

33 Sobre la actitud servicial y la legitimación para la apropiación de la ganancia empresarial, incluso desde el punto de vista moral, son especialmente iluminadoras las lecturas de Bastiat (1850) y Chafuen (1986). 
por serlo, sino que corresponde a cualquier persona por su condición humana, y desde luego niego la pertinencia de que se puedan considerar normas morales las que se deduzcan de la responsabilidad social empresarial ni siquiera por el recurso socorrido a la «ética de los negocios», más que sospechosa, dicho sea de paso, cuando vemos multiplicarse las disciplinas que con ese nombre se imparten en las escuelas de negocios.

Un punto que me parece de la mayor importancia en relación con la referencia de la responsabilidad social empresarial a intereses generales, y por lo tanto, públicos, es el que deriva de mi convicción de que sólo respetando la autonomía de los distintos ámbitos a que pertenecen los fenómenos humanos se pueden mantener para el largo plazo las condiciones que los hacen posibles. En este punto hago mía la consideración de que la empresa libre en un mercado libre es la única manera de asegurar que sea «sostenible» el desarrollo, ${ }^{34}$ de suerte que no resulta tampoco convincente la apelación a la responsabilidad social empresarial en razón de la consideración del largo plazo con que debe conducirse todo empresario. Es al empresario en relación con la concreta empresa de que se trate en cada caso a quien incumbe considerar el horizonte temporal de la empresa, contando, además, con que en la naturaleza de su función y de la empresa misma está implicada la incertidumbre y, sobre todo, la sorpresa, que se deriva de la competencia en el mercado rectamente entendida que llevan a tener que contar con la necesidad de la innovación. Y si es que con la «sostenibilidad» se alude a la necesidad de no agotar los recursos disponibles, menos convincente resulta todavía la apelación a la que me he referido porque ello es incompatible con el aspecto creativo, por no decir, creador, de la función empresarial. ${ }^{35}$

\footnotetext{
34 Rodríguez Herrera (2007).

35 Recordemos los informes del Club de Roma de hace bastantes decenios en los que se auguraba el famoso «crecimiento cero».
} 


\section{LA RESPOSABILIDAD SOCIAL Y LA SOCIEDAD MERCANTIL}

De acuerdo con el plan trazado, toca ahora analizar la cuestión de la responsabilidad social empresarial en el caso, casi general, por lo demás, de que la empresa se ejerza por una sociedad mercantil; esto es, se trata de saber la incidencia de aquella doctrina sobre el concepto y el régimen jurídico de la sociedad mercantil, para deducir la pertinencia de aquella doctrina o en dónde se localizan los puntos de fricción con el concepto de sociedad que se considera jurídicamente correcto por respetar su naturaleza y su función. Centraré la atención en el supuesto de mayor frecuencia real de que se trate de una sociedad de capital, esto es, o anónima o de responsabilidad limitada.

Es sabido que cuando en relación con una empresa figura una sociedad, desde el punto de vista jurídico ésta es el empresario, que entonces se dice ser social. Deben ser, por consiguiente, traídas aquí las consideraciones ya efectuadas más arriba acerca de la función empresarial y de la identificación del empresario en sentido económico en el supuesto de que se ejerza la actividad «externa» empresarial por una sociedad mercantil. Ténganse, pues, en cuenta particularmente las referencias anteriores a la función empresarial en el caso de una «firma».

Por consiguiente, en el caso del empresario social resultan especialmente relevantes las previsiones sobre el obrar socialmente responsable frente a grupos de interesados o stakeholders respecto de los que se efectúa la actividad «externa» de la empresa.

\section{El contrato de sociedad}

La sociedad constituida entre sujetos iguales y con un propósito de índole privada es, jurídicamente hablando, el objeto de un contrato: el contrato de sociedad, que, en atención a razones que no vienen al caso, se regula entre nosotros por el Código de comercio pero también por el civil.

Los intervinientes en el contrato de sociedad son los socios que son los aportantes del capital que se traducirá en los bienes 
de capital que la empresa precisa para su actividad, pero que se caracterizan respecto de otras personas que puedan allegar «capitales» en que ellos lo hacen afrontando el riesgo de que su aportación se pierda, de ahí que la ganancia esperada por la aportación sólo se conocerá una vez hayan sido satisfechas todas las obligaciones contraídas en el desenvolvimiento de la actividad empresarial.

Este carácter residual de la ganancia empresarial que se atribuye a los socios y que se corresponde con su asunción del riesgo, explica que se considere a la sociedad como el sujeto empresario, toda vez que además a la sociedad se le reconoce la personalidad jurídica que es el expediente técnico-jurídico para poder tratar unitariamente a un grupo humano como el que, por lo general, ${ }^{36}$ forman los socios. Por el carácter residual de la ganancia empresarial atribuido a los socios se justifica también que sea al cuerpo formado por ellos y tomado como un todo unitario al que corresponda adoptar las decisiones empresariales. No puede dudarse de que este esquema respeta puntualmente el derecho de propiedad que, como sabemos, es uno de los pilares básicos del sistema de economía de mercado. Y deseo insistir en que se respeta ese derecho tanto por lo que se refiere a los socios como también a los otros grupos de interesados que cooperan en el ámbito interno de la empresa, muy singularmente aludo a los trabajadores.

Nos acabamos de referir a la adopción de las decisiones empresariales y a estos efectos, es oportuno considerar que, puesto que tal facultad corresponde al empresario, el derecho articula el procedimiento adecuado para la formación y expresión de la voluntad unitaria del grupo de los socios. En rigor, ese procedimiento no elimina que la voluntad corresponda a los únicos sujetos reales, esto es, a los socios y por lo tanto no supone más que un expediente de técnica jurídica para poder considerar que la voluntad es la de todos y, consiguientemente, por tanto única. Por puras razones pragmáticas, se adopta el principio de mayoría.

36 La reserva que introduzco se debe a que de acuerdo con el nominalismo, que en el derecho se traduce en el legalismo positivista, hoy día se admite la sociedad unipersonal en virtud de la duodécima directiva comunitaria en materia de sociedades. 
Conviene no perder de vista de, en cuanto la obtención de la voluntad única supone conjuntar las voluntades de varios sujetos, aquélla voluntad ofrece vertientes pertenecientes al fuero externo de éstos pudiendo ser, pues, controlado por el derecho; es innegable que la decisión que pueda atribuirse a una persona jurídica se forma según un proceso que por definición es púbico en su integridad, aunque en la decisión de cada uno de los socios exista un momento de voluntariedad que se mantiene en el fuero interno de la persona y en cuanto tal inabordable para el derecho; pero desde el momento en que cada socio expresa su voluntad mediante su voto, el proceso, ya atribuible a la persona jurídica, es público y por lo mismo puede y debe ser sometido a control por el derecho a fin de salvaguardar la voluntad de cada uno y poder afirmar que el resultado es la decisión de todos. En este sentido, la importancia de salvaguardar escrupulosamente el procedimiento es la garantía para merecer la protección jurídica.

En este punto es imprescindible señalar ya que si los socios celebran el contrato de sociedad es porque se proponen hacer algo juntos, algo que no podrían conseguir de actuar por separado o que, al menos, sería de mucha mayor dificultad el conseguirlo. En este sentido, es de primordial interés tener en cuenta el llamado objeto social que es el fin para el que los socios se asocian. Y en vista del que realizan la aportación de capital que puede afirmarse que implica la transferencia del título de propiedad sobre el dinero si es que adoptamos la teoría de la transferencia de los títulos como base del contrato. ${ }^{37}$

Por otra parte, es claro que en una sociedad, también por razones pragmáticas, el proceso de la toma de decisiones empresariales se desdobla al menos, de modo que la gestión y representación aparezcan confiadas a determinadas personas físicas constitutivas del management.

El esquema de la sociedad mercantil que acaba de exponerse nos descubre sus flancos débiles cuando se adopta la perspectiva de la responsabilidad social empresarial. Esta ideología resu-

\footnotetext{
37 Rothbard(1982) pp. 187-206.
} 
cita la vieja discusión sobre el concepto contractualista o institucionalista de la sociedad mercantil, y digo resucita a pesar de que no debiera quizá suponer que semejante debate había fenecido; sin embargo es indiscutible que en los últimos lustros había perdido su vigor inicial desde que se introdujera por la ley alemana de sociedades anónimas, significativamente publicada en 1937, una referencia al «interés de la empresa en si» como paradigma de conducta en las relaciones que traen causa de la existencia de las sociedades. No me parece impertinente señalar que también esa ley obedecía al criterio inspirador del führerprinzip en cuanto que otorgaba al órgano de la administración poderes propios desligados de cualquier relación de mandato o relación representativa indicativa de los deberes que obligan al representante frente al representado.

Ha de señalarse que la concepción institucionalista responde principalmente a la gran sociedad anónima, no necesariamente abierta, aunque generalmente coincidan ambas características.

Interesa poner de relieve cuanto antes que el debate entre la concepción contractualista o institucionalista de la sociedad es independiente de la «teoría contractual de la empresa», sin perjuicio de señalar que, a mi juicio, esta doctrina es congruente más bien con la tesis institucionalista de la sociedad en cuanto que, mediante la idea de los «fallos de mercado» llega, al igual que ésta, a la conclusión de que los interés concernidos por la empresa son trascendentes a los intereses privados del empresario, sea individual o social.

Interesa también poner de relieve que aun cuando puede afirmarse, según se ha visto, que la tesis institucionalista de la sociedad arranca de la ley alemana de 1937, en realidad ésta, quizá por su fecha, no respondía a una conceptualización económica clara en el sentido que nos importa, sino que más bien se atenía a los criterios políticos del totalitarismo nacionalista del régimen alemán. Ello no obstante, es cierto que para la ley la sociedad necesariamente se pone al servicio de intereses trascendentes a los de los propios socios por representar el interés general encarnado por el Reich. No es dudoso, pues, que en este modo de ver las cosas va implícito lo característico de la concepción institucionalista, porque lo de menos será ya señalar en cada caso cuales 
sean los fines o los intereses y quiénes sean sus portadores a los que debe subordinarse $\mathrm{o}$, al menos coordinarse, el interés de los socios. ${ }^{38}$

Por su parte, la tesis contractualista ve en la sociedad mercantil un contrato que se celebra entre los socios y que tiene como finalidad un propósito que es común a todos ellos cuya consecución no puede alcanzarse en solitario, razón por la que se asocian. El contrato de sociedad se concibe en nuestros códigos como un verdadero contrato de la misma manera que se concebían como contrato las formas romanas de sociedad. Esta concepción contractual no se desdice en la Ley de Sociedades de Capital cuyo Texto Refundido se aprueba mediante Real Decreto Legislativo 1/2010, de 2 de julio. Tratándose de un contrato, su contenido consiste, como siempre, en un reglamento del comportamiento de las partes por todo el tiempo de su duración. Vincula la condición de socio a la aportación de capital de riesgo y, una vez establecida la sociedad, si con vocación de perduración más o menos larga es indiferente en cuanto que el objetivo perseguido por los socios en función del cual constituyen la sociedad consiste en la actividad empresarial, las prestaciones de las partes en el contrato no se articulan al modo de lo que suceden en las obligaciones reciprocas sino que convergen en el fin común propuesto. Por lo demás esa actividad ejercida en común requiere indispensablemente de una organización interna especialmente dispuesta para la consecución del fin social. Es digno de subrayar, que la pervivencia de la estructura organizacional que hace perdurar a la sociedad por encima de los cambios de socios, que pueden ser especialmente intensos en las sociedades anónimas abiertas y singularmente en las cotizadas, no contradice la raíz constitutivamente contractual de la sociedad dado que la organización se establece en vista y al servicio del fin perseguido por los socios al asociarse, sea en el momento fundacional o en otro posterior, y mientras mantienen su condición de tales. No existe razón alguna para, eludiendo la naturaleza contractual de la sociedad, conceder una injustificada preeminencia de la burocracia sobre

38 Rubio (1969) pp. 215 y ss. 
el carácter esencialmente personal, y por lo tanto humano, de las relaciones de los socios entre sí que surgen tan solo del contrato que ellos han tenido a bien celebrar.

\section{La representacion orgánica}

El carácter contractual de toda sociedad mercantil tiene que ser el punto de partida a la hora de plantearse la cuestión de la responsabilidad social empresarial en el caso de que el empresario sea una sociedad. Situados en ese plano, a mi juicio han de considerarse ciertos aspectos del proceso de la toma de decisiones, según la estructura organizativa de la sociedad.

Por mucho que se le reconozca a la sociedad la personalidad jurídica, es obvio que los actos y la actividad que puedan por esa razón serle imputados a ella directamente tienen que ser realizados por personas físicas o naturales que actúen por su cuenta, y, más específicamente, en su nombre, es decir, haciendo explícito en el momento de la acción que ésta se lleva a cabo para la sociedad. Para estos casos el derecho tiene establecida la institución de la representación, que, dicho sea de paso, se engloba en el mucho más amplio campo mencionado con el término agencia que es el propio de la ciencia económica y singularmente de algunas de sus corrientes de pensamiento para expresar todas las situaciones en que los actos de una persona producen sus efectos en la esfera jurídica de otra.

Como ya se señaló, razones pragmáticas indiscutibles llevan a cubrir la necesidad de que en una sociedad se atribuya a un número reducido de personas la gestión que demanda la operatividad de la sociedad. Surge así la figura de los administradores, que conjuntan en sus funciones tanto las de orden interno correspondientes al desenvolvimiento funcional del conjunto organizado empresarial como las de orden externo, es decir, frente a terceros, que son propiamente las representativas en términos jurídicos.

Uno de los puntos de mayor interés a la hora de establecer en el contrato de sociedad, bien que por vía estatutaria, la estructura de la organización es cabalmente el relativo a determinar todo 
lo que concierne a los administradores sociales. Y, puesto que, atribuirles ciertas facultades es indispensable, de ello resulta que pueda hablarse de relaciones de "poder» entre socios y administradores. Es interesante señalar que en el terreno de la actuación frente a terceros y en atención a la seguridad del tráfico las leyes establecen normas de carácter imperativo que señalan a quienes ostentan las de facultades representativas $y$, al par que determinan, el alcance de la representación. Conviene decir sin embargo que en nuestro derecho no se establecen con nitidez las competencias entre los administradores y los socios; ni siquiera en la reciente Ley de Sociedades de Capital se contiene una taxativa atribución de competencias.

Si la responsabilidad social empresarial se conecta, como es obvio, a los actos realizados en el desempeño de una empresa y, por definición, los actos reclaman un autor al que le sea imputable la responsabilidad, es evidente que los administradores se descubren como sujetos de la conducta que ha de someterse a las pautas de responsabilidad social. Pero, en términos jurídicos, una cosa es ser sujeto en cuanto autor material de un acto y otra cosa distinta es ser la persona a quien le es imputable dicho acto. A esclarecer la imputabilidad de la conducta de la que se deduzca responsabilidad social se destina el presente apartado ya que sólo después de saber cuál es la naturaleza y función del órgano encargado de la administración y representación de la sociedad estaremos en condiciones de avanzar en la valoración que merece la doctrina de la responsabilidad social empresarial desde el punto de vista jurídico.

\section{a) Los administradores y el interes social}

El desempeño de las funciones de administración y representación de la sociedad se confía en el contrato de sociedad a personas especialmente encargadas según el contrato.

Tradicionalmente esas personas, que habían de ser socios, se consideraban mandatarios de éstos para desempeñar las funciones encomendadas. La condición de mandatarios tenía la consecuencia de que al obrar el administrador o administradores con 
transcendencia en la esfera jurídica de la sociedad debían ajustar su conducta a los actos y condiciones establecidos en la relación representativa o de mandato que vinculaba a los socios. La relación representativa gobernaba pues la conducta que debían observar los administradores.

Ésta situación jurídica sufre un cambio fundamental con la publicación de la ley de sociedades anónimas de 1951 y, que se reitera luego, en el año 1953 con la publicación de la ley de sociedades de responsabilidad limitada que adoptan el criterio establecido en la tradicional doctrina alemana y que especialmente se puso de relieve, como se ha dicho, mediante la instauración del führerprinzip en la ley de 1937. En la doctrina alemana existía la tradición organicista en relación con el concepto de personalidad jurídica que se resumía en la transposición al campo de estas personas de lo que la biología nos descubre respecto de la persona física. Por virtud de esa teoría, la función de administración y de representación de la sociedad se considera por completo separada y distinta de cualquier otra función, singularmente la de formar la voluntad del cuerpo de socios. Una y otra de estas funciones, como incluso de otras posibles, se encomendaban, también por simetría con la concepción biológica de la especie humana, a órganos distintos de la propia persona jurídica que disfrutaban, pues, de su propia y exclusiva competencia. El órgano de la administración podía encontrarse servido por personas que no fuesen socios, con lo que se pudo hablar del organicismo de terceros. Semejantes consideraciones se impusieron con referencia a aquellos tipos de sociedad respecto de los que el derecho alemán y su doctrina reconocían la personalidad jurídica, como eran la sociedad de responsabilidad limitada y la sociedad anónima.

La teoría organicista en nuestro sistema jurídico no podía tener justificación por razón de la personalidad jurídica atribuida a la sociedad dado que en nuestro sistema, a diferencia del alemán, todas las sociedades disfrutan de personalidad jurídica. De ahí que, entre nosotros, la teoría organicista se ordena a explicar el contenido rígido de los poderes atribuidos por la ley a los administradores. Ciertamente la superación de la teoría del mandato como relación representativa capaz de sustentar la acción de representación de los administradores podría dificultar quizá la 
consideración de que éstos disfrutaban de facultades rígidas necesarias para producir la seguridad al tráfico por la confianza de los terceros en que los actos realizados por los administradores vinculan a la sociedad. Sin embargo la cuestión del contenido de los poderes rígidos en beneficio de la seguridad del tráfico no es algo esencialmente vinculado a la naturaleza orgánica de la representación, y en consecuencia si se tratare de la necesidad de proteger la seguridad del tráfico podía abordarse según las técnicas habituales de protección de terceros.

A mi juicio, en realidad la doctrina de la representación orgánica se importa por el legislador español del 51 porque, además de su abolengo doctrinal a la sazón indiscutido, se considera más apropiada a la estructura de la sociedad anónima como forma predispuesta para una sociedad con elevado número de socios e incluso abierta. Tenía menos justificación, por eso mismo, en relación con la sociedad de responsabilidad limitada; en todo caso, incluso respecto de las anónimas, era discutible por la «polivalencia» de este tipo societario en nuestro derecho.

Calificar de orgánica la representación no deja de tener importantes consecuencias en el orden de las relaciones entre el órgano representativo y el cuerpo de los socios, ahora también considerado órgano y, en teoría, soberano. En primer lugar, se facilita la concepción de la gestión y administración e incluso de los actos de representación como actividad profesional que postula, por lo general, una notable especialización, razón por la cual no tiene que ser desempeñada la función por socios sino por terceros ajenos a la sociedad, de donde se sigue que la compensación económica que los administradores han de recibir deben obtenerla en razón de sus servicios y, en principio, con desconexión de las ganancias obtenidas por el ejercicio empresarial.

En segundo término, se hace honor ciertamente al principio fundamental en una economía de mercado de la protección de la seguridad del tráfico al facilitar la comprensión de que los actos realizados por el órgano administrativo frente a terceros de buena fe sean imputables a la sociedad y, por consiguiente deben vincularla a ella. Pero la teoría orgánica se lleva, a mi juicio, más allá de lo estrictamente preciso para salvaguarda del mencionado principio cuando a aquel órgano se le atribuyen ex lege unas 
concretas competencias, porque entonces parece que éstas son originarias $\mathrm{y}$, por tanto, que se pueden ejercer independientemente del otro órgano social, en teoría soberano. La teoría orgánica contribuye a dejar establecida la cuestión del «poder», llamado «control», en la sociedad, de tal modo que, concebido en favor del órgano administrativo, se coloca en tensión con la "propiedad»; lo que presupone la separación entre uno y otra representando un despojo de una de las funciones esenciales de la propiedad y, en definitiva, una expropiación de su valor. Razón, por la que para remediar en parte el despojo, se articula la extravagante doctrina de la «creación de valor» para el socio, que no ha dejado de contribuir de modo singular a las crisis de los noventa.

La cuestión del poder se torna especialmente problemática y sobre ella pivota toda la doctrina que considera a la sociedad como institución. Porque, si los administradores son un órgano de la sociedad misma y ésta tiene unos fines distintos y transcendentes a los definidos por el cuerpo de los socios, la atribución ex lege de competencias exclusivas al órgano de la administración exige que los administradores actúen en vista de los intereses de la sociedad, como sujeto de derecho distinto de estos socios.

Mediante la teoría de la representación orgánica se rompe toda referencia a la relación representativa entre socios y administradores y, siendo así que en esa relación tiene su fundamento el aspecto de deber del representante hacia su representado por lo que se refiere a la acción representativa del primero, es claro que se dificulta, aunque no llegue a desaparecer del todo la función de control o vigilancia que corresponde a los socios respecto a los administradores. Y no llega a desaparecer del todo porque es verdad que a los socios corresponde especialmente la revocación del nombramiento de administradores (Cfr. art. 223 LSC) y que, salvo excepciones que no vienen al caso, ${ }^{39}$ para la revocación del nombramiento no es necesario invocar justa causa (cfr. art. 223 LSC) datos normativos éstos que expresan un vínculo de dependencia de los administradores respecto de los socios. Por debilitado que

${ }^{39}$ La posible excepción se refiere al cese de los miembros del consejo de administración designados por la minoría cuando se ha utilizado el sistema proporcional para el nombramiento. Sobre el particular Sánchez Calero (2010) p. 515. 
se encuentre, pues, ese vínculo de dependencia, es indiscutiblemente suficiente para considerar que, pese al carácter orgánico que a determinados efectos proceda a otorgarse a la función de los administradores, no dejan éstos de participar de la naturaleza de la institución jurídica de la representación ni los actos representativos dejan de ejercerse por cuenta de los socios unificados en la sociedad.

Y es que calificar de orgánica a la representación no implica negar como es obvio que los administradores actúen como representantes de otro. ${ }^{40}$ Incluso puede admitirse que aquel sujeto cuya esfera jurídica queda afectada por el acto del representante orgánico es el mismo ente jurídico al que pertenece el órgano, pero a condición de que se entienda correctamente el concepto de persona jurídica que conviene a la sociedad a fin de que no se traicione su esencial carácter contractualista ni, por lo tanto, el servicio de los socios.

No hay inconveniente en aceptar que, en la representación orgánica, la representada es la sociedad de la cual es el órgano, siempre que por ésta se entienda el grupo de socios establecido sobre la base de un contrato. Centrada así la cuestión, es indudable que, como representantes de la sociedad, los administradores han de comportarse de acuerdo con un deber de fidelidad a los socios en cuanto tales, es decir, a los socios en cuanto miembros del grupo llamado sociedad. Se puede, pues, afirmar que los administradores actúan como fiduciarios de los socios. Y, existiendo entre administradores y socios una relación representativa, bien que formalmente mediada por la sociedad, los administradores han de ajustar su conducta a los intereses de los socios en tanto que tales, esto es, en tanto que los intereses se han unificado gracias al ente societario del tal modo que se puede hablar del interés social. El interés social no es un interés perteneciente a un sujeto distinto de los socios ni siquiera es un interés de la sociedad sino que es el interés de los socios en sociedad.

El interés social constituye pues el referente para la actuación de los administradores coherente con su función de representantes

\footnotetext{
40 Díez-Picazo (1979) pp. 287 y ss.
} 
del cuerpo de socios integrado en la sociedad. Son bien conocidas las dificultades que encierra la definición del interés social y por lo tanto las imprecisiones inherentes al hecho de hacerlo centro referencial de la actuación diligente de los administradores y por esto mismo en relación con la responsabilidad social empresarial. ${ }^{41}$

Las dificultades, que, por lo demás no difieren de las que se presentan en prácticamente todo análisis jurídico, no deben llevarnos sin embrago a la aceptación de que por tratarse de un concepto indeterminado puede llenarse con cualquier contenido que la ideología nos sugiera. Parece desde luego indudable que el interés social no puede albergar intereses de los que son portadores otros grupos ajenos a la sociedad, y nótese que hablamos de sociedad que no de empresa porque el grupo de los trabajadores puede considerarse interno a ésta última pero, desde luego, es rigurosamente externo al grupo societario.

Siendo así las cosas, creo poder concluir que en ningún caso la responsabilidad social empresarial puede afectar a los administradores sociales en el sentido de que se les pueda exigir a ellos en su condición de administradores que observen de ningún modo las pautas que de aquella responsabilidad se deduzcan cuando no vengan impuestas por una norma legal; sí deberán someterse a ellas cuando la decisión de tenerlas en cuenta en la práctica de la concreta sociedad de que se trate proceda de los propios socios. ${ }^{42}$

41 Que en nuestro derecho se concibe el interés social como el interés de los socios se sostiene inequívocamente por la jurisprudencia del Tribunal Supremo. Ni siquiera la modificación textual de algunos preceptos de la Ley de sociedades anónimas, que se mantienen en la nueva Ley de Sociedades de Capital, permiten pensar que no sea así, como sostiene Sánchez-Calero(2006) pp. 96 y ss.; en contra, Esteban (2005) pp.47 y ss. Es pertinente señalar que el interés social constituye referencia incluso para ponderar la validez de los acuerdos de socios en la junta general, con lo que, por cierto, se pone de relieve el deber de todos los socios de obrar con recíproca lealtad según impone el contrato de sociedad; en este sentido, los socios del «control» (a los que suelen deber sus cargos los administradores) deben comportarse respecto de los llamados «minoritarios» de modo que no sufran expolio de su propiedad como estarían expuestos a sufrirlo de aceptarse la concepción institucionalista de la sociedad.

42 En la dirección que se indica en el texto se encuentra lo dispuesto en el Código Conthe de Buen Gobierno de las Sociedades Cotizadas. Sobre él, Lizcano (2006). El Código nos ilustra acerca de la voluntariedad de las prácticas de responsabilidad social empresarial, acerca del concepto de interés social como interés de los socios 
Es oportuno no obstante subrayar que de que no pueda exigírseles a los administradores observar las pautas que se deduzcan de la responsabilidad social empresarial no impuesta por ley no se sigue necesariamente que no deban conformar su conducta a ellas, puesto que precisamente en consideración de sus deberes fiduciarios respecto del interés social pueden tener que hacerlo para que su conducta sea considerada diligente. Debe recordarse cuanto antes se dijo acerca de la coacción desde instancias sociales expresiva del consenso sobre la actuación socialmente responsable. De ser así, tendrá que convenirse en que la responsabilidad social empresarial afecta en grado sumo al concepto y naturaleza de la sociedad mercantil y a las consecuencias de uno y otra en la naturaleza y función de los administradores de la sociedad.

Excusado es decir que el parecer que acabo de exponer sería extrapolable, y con mayor razón, al supuesto de que la responsabilidad empresarial se impusiera legalmente. En ese caso se plantearía un delicado problema de interpretación de las normas legales mientras se mantuvieran las que hoy todavía fundamentan la teoría contractualista de la sociedad mercantil, aunque quizá quepa dar por seguro que la ideología dominante llegaría a imponerse, con las consecuencias, a mi juicio, negativas tanto en el plano de la corrección conceptual como en el de la praxis de la actividad económica que, por ser libre, se ha acreditado como más fructífera, y que debe ser sostenida por el derecho según puede deducirse de lo que, por mi parte, aquí sostengo.

\section{b) Los administradores y el objeto social}

El interés social tiene mucho que ver con otro elemento conceptual indispensable, en general, al tratar de las sociedades, pero, en especial, para nosotros en este momento. Se trata del objeto social.

\footnotetext{
y asimismo de la necesidad de que los inversores en acciones, que por ello se conviertan en socios de la emisora, conozcan que en ésta los socios tienen adoptadas decisiones respecto a dicha responsabilidad. Todo lo cual concuerda con lo que en el texto se mantiene.
} 
Su referencia es obligada para completar el análisis de la actuación de los administradores, incluso bajo su consideración orgánica, en relación con la responsabilidad social empresarial. Si el interés social nos ha servido para negar la pertinencia de semejante tópico desde la perspectiva de la sociedad stricto sensu, el objeto social nos será útil para juzgarlo desde el punto de vista de las relaciones que pueden adscribirse al ámbito de la empresa que la sociedad ejerce y sobre la que, por lo tanto, recae la acción de los administradores. Pero antes de pasar al análisis específico de esa materia, cosa que efectuamos en el siguiente epígrafe, es imprescindible detenerse en considerar la significación del objeto social para la relación de sociedad misma.

No es el momento de entrar en las cuestiones que plantea el objeto social por referencia a lo que es objeto del contrato teniendo en cuenta la naturaleza contractual de la sociedad. Tampoco merece nuestra detención la discutible distinción entre objeto y fin social. ${ }^{43}$ En mi opinión, con el objeto social o el fin social se menciona la actividad que va a desarrollar la sociedad y en función de la cual se justifican, ordenan o articulan los pactos y cláusulas organizativas, así como también en consideración al objeto se han de realizar por los socios las prestaciones de medios necesarios para el ejercicio de esa actividad. El objeto social es, por lo tanto, un elemento esencial al contrato de sociedad como el objeto del contrato es esencial a todo contrato (cfr.art. 1.261 CC). De otro lado, el objeto social es determinante del interés de todos los socios confluyente en la sociedad, es decir, es determinante de la configuración del interés social al que antes nos hemos referido.

Se comprende que la referencia al objeto social constituya una de las menciones esenciales de la escritura pública que en su caso dé forma al contrato social (cfr. arts. 23 LSC y 209 RRM). En el caso de no existir escritura, resulta asimismo esencial por exigirlo el artículo 1.261 del Código civil.

Es cuestionable sin embargo el grado de determinación con que debe expresarse el objeto social. Es mayoritaria la doctrina

43 Sobre el particular, por todos, Girón (1976) pp. 198 y ss. 
que acepta, seguramente con base en las normas positivas, una cierta indeterminación. Ciertamente esta posición es congruente con la vocación de permanencia o duración de la sociedad y con la ignorancia de los socios respecto del futuro. No resulta en verdad congruente una vinculación de los socios por tiempo indefinido con la expresión de la actividad a que la sociedad se dedicará en una forma tan rígida que la impidiera adaptarse a las nuevas situaciones. Esto resulta especialmente cierto si el objeto social viene constituido por una actividad empresarial.

En nuestra situación damos por presupuesto que la actividad a la que se dedicará la sociedad es una actividad lucrativa, y específicamente una empresa de producción de bienes y servicios y de intercambio de éstos en el mercado. En este sentido, se puede hablar de que el objeto social se confunde con la empresa que va a ejercitar la sociedad.

No parece necesario abundar en la necesidad de dejar abierta la definición del objeto social en nuestro caso. Pero interesa, no obstante, señalar que la indeterminación no debe llegar al extremo de que se pueda estimar permisible una verdadera transformación o cambio de la actividad al margen de las vías jurídicas previstas para alterar el contrato de sociedad, que no siendo un contrato de cambio, exige su modificabilidad en atención al fin para dar cabal cumplimiento al indeclinable principio pacta sunt servanda, que es también pilar de una economía libre o de mercado.

Como siempre ha de ser una razón prudencial la que en cada caso determine el modo en que se tiene que expresar el objeto social en el contrato así como juzgar si determinados actos quedan o no incluidos en él. Por mi parte, estimo que el género de la actividad, que se confunde con el género de empresa en nuestro caso, debe ser suficientemente precisado sin necesidad de llevar las decisiones más allá y por supuesto sin necesidad de especificar los actos concretos en que la actividad ha de traducirse.

Sentado lo anterior, corresponde sin duda a los administradores de la sociedad las facultades precisas para el desarrollo de la actividad constitutiva del objeto social pero debe estarles vedado realizar actividades ajenas al objeto social. La razón de esto se encuentra en el respeto con que deben conducirse los administradores hacia el interés social que, como hemos señalado, se 
especifica alrededor del objeto social. Este sólo puede ser disponible por los socios en cuanto que constituye un elemento estructural de la sociedad.

Hasta tal punto es así que en el sistema jurídico británico, tan ajeno a las construcciones dogmáticas y abstractas, la capacidad de la sociedad se delimitaba en torno al objeto social, de tal modo que los actos extraños a él se consideraban ultra vires y, en consecuencia, nulos e ineficaces. La teoría de la capacidad general de la persona jurídica, aportación del sistema alemán, que significa su aptitud para realizar cualquier tipo de actos, es el adoptado entre nosotros, pero no ha de significar sin embargo que, según eso, el objeto social no sea definitorio de las facultades propias del órgano de representación, sin perjuicio de que el obrar en exceso de esas facultades no invalide el acto para protección de la seguridad del tráfico.

No es este el momento para detenerse en los problemas que plantea la posible constancia y repetición de actos extraños al objeto social por parte de miembros del órgano representativo, ${ }^{44}$ pero entiendo que debe mantenerse la tesis de que por esa vía fáctica no puede atentarse contra el significado que, en un sistema contractualista como el nuestro, el derecho otorga al objeto social como parcela en torno a la cual se define el interés de cada socio por concluir el contrato de sociedad y cuya importancia se pone de manifiesto con el régimen jurídico positivo establecido en nuestro derecho de sociedades ${ }^{45}$ para el supuesto de cambio de objeto social durante la vida de la sociedad, régimen que aun en el más liberal de los supuestos (cfr. art. 346.1(a)LSC) implica que el socio disconforme con la mayoría, que además ha de ser reforzada al menos para la sociedad anónima (cfr.art. 201.2 en relación con art. 194(1), ambos de LSC), tiene la facultad de separarse de la sociedad.

De lo dicho concluimos que tampoco desde el punto de vista del objeto social resulta consistente con el régimen jurídico

${ }^{44}$ Sobre el objeto social, Sáez García de Albizu (1990), passim; Rodríguez Artigas (1994), passim pero especialmente pp. 168 y ss.

${ }_{45}$ Rodríguez Artigas ob. loc. cit; Valpuesta (2007) pp. 372 y ss., con abundante cita jurisprudencial. 
positivo que los administradores hayan de atender cometidos extraños a ese objeto. De nuevo conviene insistir en que una imposición legal de ese orden implicaría un contrasentido con el sistema de nuestro derecho de sociedades, que, por lo demás, es el consistente con una economía de mercado.

\section{c) Los administradores y el ejercicio de la empresa social}

Nótese que por hipótesis estamos ante el hecho de que el objeto social en nuestro caso viene constituido por el ejercicio de una actividad empresarial. En realidad, en relación con la empresa que ejerza la sociedad se proyecta lo que acabamos de decir sobre el objeto social y los administradores con referencia a la incidencia en el ámbito de la relación societaria, de la misma manera que también se proyecta lo que igualmente hemos dicho sobre los administradores y el interés social en aquel mismo ámbito.

Ha de darse por reproducido aquí buena parte de lo que se expuso en epígrafes anteriores. Hablar de la responsabilidad social con que debe ejercerse una empresa es, sin duda, redundante porque en el concepto mismo de la empresa, así como de la función empresarial, va ínsita la referencia a la sociedad civil. Se tome el término social en el sentido que se tome es clara la proyección social de la empresa así como, recíprocamente, la proyección del sistema social en la empresa.

Creo que no es necesario ni por otra parte sería útil detenerse en la dimensión social de cualquier fenómeno empresarial en términos generales. Habría que repetir cosas ya dichas. En este sentido es obvio que la responsabilidad social empresarial no puede tener ese significado, como también se ha dicho.

Únicamente acaso y en atención al supuesto de un empresario social, convenga insistir en algunos puntos que abundan en las consideraciones ya expresadas con anterioridad pero realizadas en términos generales del ejercicio empresarial y por consiguiente sin cuidado del carácter del empresario.

Recordemos tan solo que, según se dijo, la responsabilidad social implica la actuación empresarial según pautas de conducta que impone el bienestar de la sociedad civil en su conjunto así 
como el respeto a los llamados bienes públicos eliminando o compensando de algún modo las externalidades inducidas por el ejercicio de la empresa. Es decir con la responsabilidad social empresarial se alude a un plus de objetivos que sin embargo no vienen jurídicamente exigidos.

Pues bien, en el caso de la empresa ejercida por una sociedad mercantil no hay circunstancias que aconsejen variar las conclusiones a que llegamos al tratar en términos generales de la responsabilidad social empresarial. Únicamente, conviene insistir acaso en que, al margen de lo concerniente al empresario «puro», a la «firma», es decir, a la sociedad, le está atribuida la titularidad de la empresa en el sentido que sabemos puesto que sólo así se respeta el juego del derecho de propiedad como eje de la actividad económica libre. De este modo, todos los hipotéticos grupos de interesados en la actividad empresarial según la responsabilidad social empresarial son extraños al empresario propiamente dicho. Concebido éste como un grupo constituido por medio de un contrato, a las partes en dicho contrato corresponde decidir acerca de los actos y de la actividad en que se traduzca la función coordinadora del empresario, sin que los administradores sociales puedan sentirse emancipados de sus deberes fiduciarios frente a la sociedad como grupo de los socios. Por consiguiente, sólo en la medida en que los requerimientos de la responsabilidad social empresarial sean consistentes con lo que aquellos deberes exigen, estarán obligados los administradores a secundarlos.

En consecuencia con lo anterior creo que puede aceptarse como hipótesis que los administradores sociales están facultados para atender el interés de los grupos afectados por la acción empresarial cuando, por estar en cierto modo relacionados con la empresa, la satisfacción de esos intereses redunden en beneficio de la empresa misma, porque en tal caso las acciones $\mathrm{u}$ omisiones pertinentes se podrán adscribir al interés social, o sea, al común de los socios. Nótese que en este campo se ha de tener una amplitud suficiente para admitir que procede asignar recursos por los administradores incluso en razón de estrategias informadas por la oportunidad o conveniencia que deben considerarse incluidas en la perspicacia o sagacidad del empresario. 
En este punto sin embargo no está de más referirse a que, a menudo, acciones conexas a la responsabilidad social empresarial en el campo de la atención de los intereses hasta cierto punto internos a la sociedad se justifica por la consideración del largo plazo que, a su vez, se traduce en el caso de una empresa social en la pervivencia de la sociedad. Pues bien, por mi parte considero que esta pervivencia no es cuestión sobre la corresponda decidir al órgano de la administración. Determinar la duración de la relación de sociedad es cuestión que únicamente corresponde a los socios. Por lo tanto, considero inaceptable que acciones de responsabilidad social empresarial puedan decidirse por el órgano administrativo en atención a la consideración del largo plazo. Aquí va implícito por lo tanto toda esa discutible referencia a la sostenibilidad de la economía. Supuesto que fuera procedente el concepto de sostenibilidad en sí mismo, cosa que pongo en seria duda, de ninguna manera el concepto de sostenibilidad que parece poder deducirse de la nebulosa de sus referencias puede justificar una decisión del órgano administrativo que oriente a esos fines los recursos dispuestos por los socios y a su cargo para el ejercicio de la actividad empresarial constitutiva del objeto social.

Por otra parte, sin embargo el ambiguo contenido de la responsabilidad social empresarial permite que con frecuencia se reconozca que en su contenido se integra la atención a las externalidades negativas que operan respecto a los grupos de interesados absolutamente ajenos a las relaciones empresariales y con los que no existe más vínculo que el de la humana convivencia. No hay que decir que muy particularmente me refiero a la preocupación por el medio ambiente y a la defensa de los derechos humanos en los ámbitos que determinan el fenómeno de la globalización, así como la promoción de la igualdad y cosas semejantes. Pues bien, la prevención de las externalidades negativas, caso de que existieran, de ninguna manera corresponde atenderlas a los administradores sociales.

Ahora bien, parece adecuado reiterar una vez más que en todo caso han de estimarse injustificados los requerimientos derivados de la responsabilidad social empresarial que de cualquier modo se manifiesten coercitivos, por representar una errónea 
concepción de la empresa, del empresario y del mercado en que pretenden fundamentarse que, si infecunda y hasta perniciosa en el campo de la economía, es incongruente con el derecho a la libertad de empresa en una economía de mercado establecido en la Constitución.

\section{La junta de socios y las prácticas de responsabilidad social empresarial}

No quisiera que pudiera deducirse del epígrafe anterior que las prácticas incursas en la responsabilidad social empresarial resultan plenamente justificadas en derecho cuando vienen determinadas por decisiones de la junta general o asamblea de los socios.

Temo que la deducción pudiera venir provocada por el hecho del papel que se ha otorgado anteriormente tanto al interés social como al objeto social. Puesto que uno y otro nos han servido para poner en cuestión, y en todo caso limitar, las facultades del órgano administrativo en relación con las prácticas de la responsabilidad social empresarial podría parecer que dichas prácticas son plenamente adecuadas cuando encuentran su respaldo en resoluciones del cuerpo de socios. Sin embargo no es en modo alguno así.

Para establecer una duda más que razonable acerca de la pertinencia de que los socios hayan de atender a las pautas establecidas sobre la base de la responsabilidad social empresarial se alza ante todo la conceptualización rigurosa de lo que es una empresa mercantil. Repitamos que, dado que la atención al grupo de trabajadores, proveedores y consumidores está siempre ínsita inevitablemente en toda acción empresarial, resulta sencillamente inadecuada e injustificada la invocación a una supuesta responsabilidad social empresarial de ninguna manera necesaria. Si algún sentido puede tener la invocación a la responsabilidad social empresarial es por referencia a todo ese conjunto proteico de atenciones que no se refieren a ninguno de los grupos que podemos llamar internos a la acción empresarial y en este caso también se impone la necesidad de volver la mirada tanto al interés social como al objeto social. Porque aún cuando uno y 
otro se definan por los propios socios, sus perfiles vienen determinados por la circunstancia de encontrarse en sociedad esos sujetos. El interés social es sí el interés de los socios, pero el interés de los socios en sociedad. El objeto social es sí la actividad que han decidido realizar los socios, pero es la actividad realizada en sociedad. La referencia absoluta al contrato de sociedad somete pues cuanto al interés y al objeto social se refiere al ámbito contractual y a la consiguiente estructura societaria que de él deriva y que sostiene a la sociedad.

Por lo que toca al interés social, no parece necesario subrayar en este momento que no significa un interés de la sociedad en cuanto tal que sea transcendente y superior al interés propio de los socios, sino que es el interés de éstos pero que se actualiza mediante la sociedad. En este sentido, la disponibilidad del interés social por los socios no supone que cada uno de ellos pueda definirlo o disponer sobre él. Estas funciones se otorgan a la junta general o asamblea de socios cuyos acuerdos se someten cabalmente al respeto del interés social. ${ }^{46}$

Por lo que se refiere al objeto social, debe tenerse por reproducido lo que dijimos ya sobre él. Recuérdese únicamente que, si bien la actividad empresarial constitutiva del objeto social puede cambiarse por acuerdo de los socios, la importancia de su determinación es tal que el cambio justifica que el socio que no haya votado a favor pueda separarse de la sociedad.

\section{REFERENCIAS BIBLIOGRÁFICAS}

Argandoña, Antonio y Von Weltzein, Heidi (2009): «Corporate social resposibility: one sixe does not fit all. Collecting evidence from Europe» en http:/ / www.profesionalesetica.org/ 2010/02/22/argandona-y-von-weltzein-en-la-rse-no-hayuna-solucion-que-valga-para-todo/

BASTIAT, FRÉDÉRIC (1850): Armonías económicas, Madrid (2010), Instituto Juan de Mariana.

\footnotetext{
46 Véase nota 42.
} 
Bercovitz, Alberto (2010): «Responsabilidad social del empresario», Estudios de Derecho Mercantil. En memoria del Profesor Aníbal Sánchez Andrés. Madrid, Civitas: 65-76.

Chafuen, Alejandro (1986): Raíces cristianas de la economía de libre mercado, Madrid (2009), EL Buey Mudo.

CoAse, Ronald (1988): La empresa, el mercado y la ley, Madrid (1994), Alianza Editorial.

De la Cuesta Rute, José María (1982): «Incidencia del Balance Social en la estructura jurídica de la Sociedad Mercantil» en El Balance Social de la Empresa y las Instituciones Financieras (VV.AA.), Madrid, Banco de Bilbao.

DíEz-PicAzo, Luis (1979): La representación en el derecho privado, Madrid, Civitas.

EMBID, José Miguel (2004): «La responsabilidad social corporativa ante el Derecho Mercantil», Cuadernos de Derecho y Comercio, N.․ 42: 11-44.

EsteBAN, GAUDENCIO (2005): «Interés social, buen gobierno y responsabilidad social corporativa (algunas consideraciones desde una perspectiva jurídico societaria)» en Responsabilidad social corporativa, aspectos jurídico-económicas. Castellón de la Plana, Publicacions de la Universitat Jaume I: 13-62.

Friedman, Milton (1970): «The Social Responsibility of Business is to Increase its Profits», The New York Times Magazine. 13 de septiembre. http:/ / www.colorado.edu/studentgroups/ libertarians/issues/friedman-soc-resp-business.html

Giron, José (1976): Derecho de Sociedades, Madrid.

GONDRA, JOSÉ MARÍA (2010): «La teoría contractual de la sociedad anónima: una aproximación a sus fundamentos teóricoeconómicos». Revista de Derecho Mercantil, N.․278: 1171-1231.

HAYEK, FRIEDRICH (1952): La contrarrevolución de la ciencia. Estudios sobre el abuso de la razón, Madrid (2003), Unión Editorial.

HuerTa DE SOTO, Jesús (2004): «La teoría de la eficiencia dinámica», Procesos de Mercado, Vol. I, N.․ 1: 11-71

- (2008): The Austrian School. Market Order and Entrepreneurial Creativity, Cheltenham (UK) y Northampton (USA), Edward Elgar Publishing.

KIRZNER, ISRAel (1973): Competencia y empresarialidad, 2. ․․ ed. Madrid (1988), Unión Editorial. 
LizCANO, José LUIS (2006): «Buen gobierno y responsabilidad social corporativa» en http:/ / partidadoble.wke.es/noticias base/buen-gobierno-y-responsabilidad-social-corporativa?locale $=$ es\&magazine_ids $\% 5 \mathrm{~B} \% 5 \mathrm{D}=1 \& \mathrm{q}=$ lizcano\&site $=4$

Mises, Ludwig Von (1949): La acción humana, 6. ․ ed. Madrid (2001),

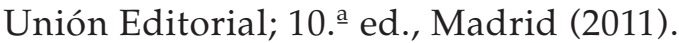

Olcese, Aldo (2009): El capitalismo humanista, Madrid, Marcial Pons.

RALLO, JUAN RAMÓN (2011): «No es un juego de suma cero» en http:/ / www.libertaddigital.com/opinion/juan-ramon-rallo/noes-un-juego-de-suma-cero-58914/.

Rodríguez ARTigas, FernANDo (1994): «El cambio de objeto social. En particular, el derecho de separación del socio» en Derecho de Sociedades Anónimas III. Modificaciones de estatutos. Aumento y reducción del capital. Obligaciones. Volumen 1. (VV.AA.). Madrid, Civitas.

Rodríguez Herrera, Daniel (2007): «El mercado libre es el único desarrollo sostenible posible» en:

http: / / www.juandemariana.org/comentario/1410/ mercado/libre/unico/desarrollo/sostenible/

Rothbard, Murray (1982): La ética de la libertad, Madrid (2009), Unión Editorial.

Rubio, Jesús (1969): Introducción al Derecho Mercantil, Barcelona, Nauta: passim.

Saenz García de Albizu, Juan Carlos (1990): El objeto social en la sociedad anónima, Madrid, Civitas.

Sánchez Calero, Fernando y Sánchez-Calero Guilarte, Juan (2010): Instituciones de Derecho Mercantil. Volumen I, Cizur Menor, Aranzadi.

SÁNCHEZ-CALERO, JuAN (2006): «Creación de valor, interés social y responsabilidad social corporativa» en Derecho de sociedades anónimas cotizadas (Rodríguez Artigas et al. coords.), Cizur Menor, Aranzadi como Tomo II: 851-913.

Schwartz, Pedro (1981): Empresa y Libertad, Madrid, Unión Editorial.

VAlpuesta, EduARdo (2007): Sociedades anónimas y de responsabilidad limitada: legislación concordada, jurisprudencia y bibliografía, Cizur Menor, Aranzadi. 
VALERDAS, ÁNGEL (2010): «Aproximación jurídica a la responsabilidad social corporativa» en Responsabilidad social de la empresa y derecho mercantil (Alfonso, R. dir. y coor.), Granada, Comares: 3-29.

VV.AA (1982): El Balance Social de la Empresa y las Instituciones Financieras, Madrid, Banco de Bilbao.

- (1994): Derecho de Sociedades Anónimas III. Modificaciones de estatutos. Aumento y reducción del capital. Obligaciones. Volumen 1, Madrid, Civitas.

- (2005): Responsabilidad social corporativa. Aspectos jurídicoseconómicos, Castellón de la Plana, Plublicacions de la Universitat Jaume I.

- (2010): Responsabilidad social de la empresa y Derecho mercantil, Granada, Comares. 